\section{Journal of Educational}

and Psychological Sciences

Volume (6), Issue (8): 28 Feb 2022

P: $112-132$

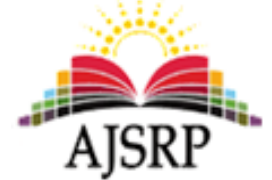

ISSN: 2522- 3399

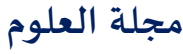 \\ التربوية والنفسية \\ المجلد (6)، العدد (8): 28 فبراير 2022 م \\ ص: 112 - 132
}

\title{
The predictive ability of emotional representation and self- satisfaction among the students of the upper basic stage of the Syrian refugees in the schools of the Directorate of Education of the Giza District
}

\author{
Salah Sanad Al-Samor \\ Directorate of Education of the Giza District || Ministry of Education || Jordan
}

\begin{abstract}
The current study aimed to reveal the level of both emotional representation and self- contentment among students of the upper basic stage of Syrian refugees in the schools of the Directorate of Education of the Giza District, and to identify the nature of the relationship between emotional representation and self-contentment, and to determine the possibility of predicting the level of self- contentment through the level of emotional representation. The study used the descriptive analytical method, and the study sample consisted of (185) male and female students, who were chosen by random method, and two scales were applied to them, namely the emotional representation scale and the self- contentment scale, and the study concluded that there is an average level of emotional representation and self- contentment among students, and a positive relationship between emotional representation and self-contentment among students. Differences in emotional representation due to gender and in favor of females, while it was found that there were no differences in subjective contentment due to gender.
\end{abstract}

Keywords: predictive ability, emotional representation, self- contentment, upper basic stage students, Syrian refugees.

\section{القدرة التنبؤية للتمثل العاطفي والهناء الذاتي لدى طلبة المرحلة الأسـاسية العليا من اللاجئين السيوريين في مدارس مديرية التربية والتعليم بلواء الجيزة

\author{
صلاح سند السمور \\ مديرية التربية والتعليم بلواء الجيزة || وزارة التربية والتعليم || الأردن
}

\begin{abstract}
المستخلص: هدفت الدراسة الحالية إلى الكشف عن مستوى كل من التمثل العاطفي والهناء الذاتي لدى طلبة المرحلة الأساسية العليا

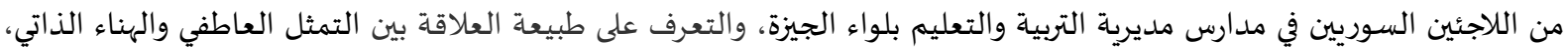

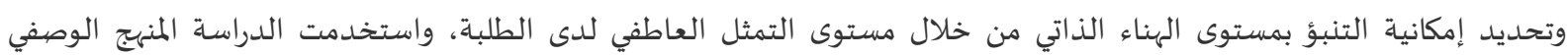

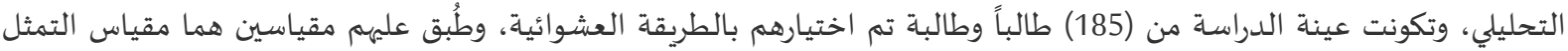

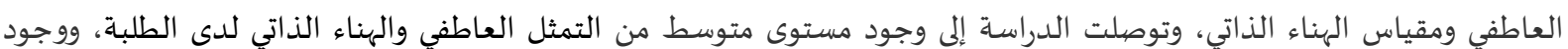

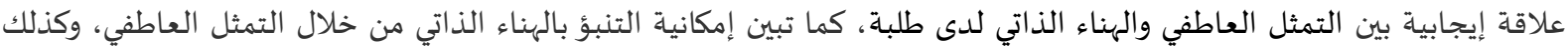
تبين وجود فروق في التمثل العاطفي تعزى للجنس ولصالح الإناث، بينما تبين عدم وجود فروق في الهناء الذاتي تعزى للجنساء الكلمات المفتاحية: القدرة التنبؤية، التمثل العاطفي، الهناء الذاتي، طلبة المرحلة الأساسية العليا، اللاجئون السوريين.
\end{abstract}


يؤدي الجانب الاجتماعي في حياة الفرد دوراً، وفي جميع تفاعلاته وعلاقاته مع الآخرين، فالفرد الناجح والذي يمتلك المهارة الاجتماعياة، والذي يعرف كيفية التحكم بمشاعره، والكفوء في قراءة مشاعر الآخرين، ويتعامل معها بصورة جيدة، فهو بذلك يكون لديه القدرة على التكيف مع مختلف مجالات الحياة، ومنها المجال العاطفي.

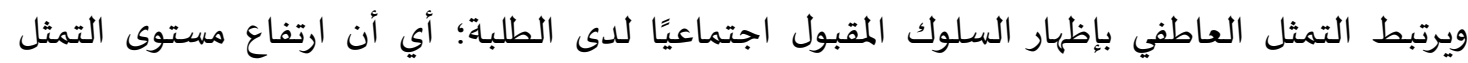

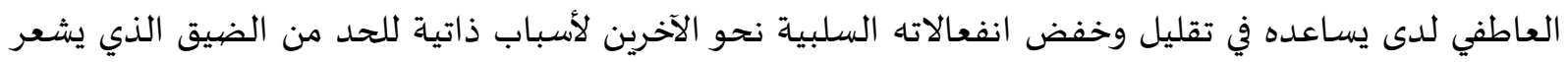

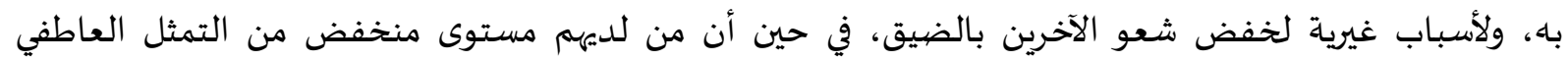

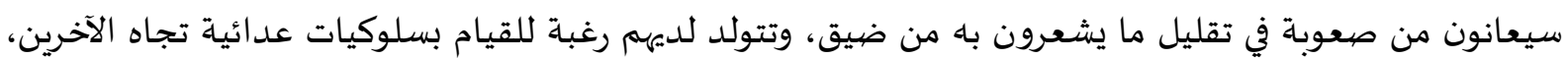

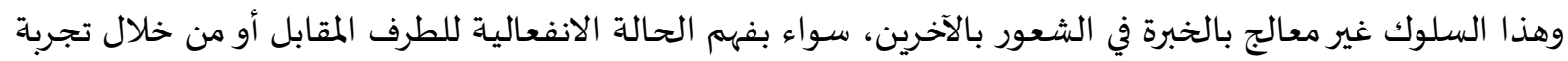

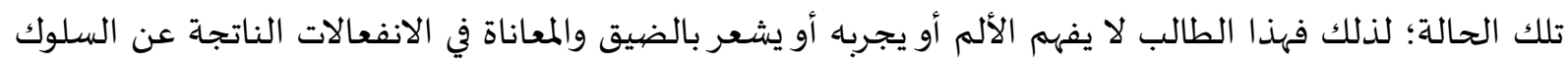

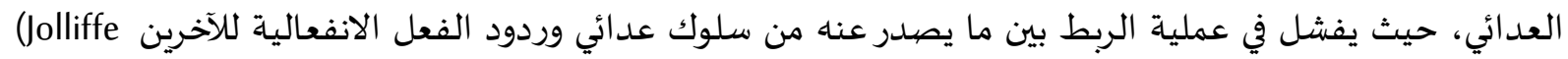

.\& Farrington, 2009)

ويُعرف التمثل العاطفي بأنه الدخول إلى العالم الإدراكي للشخص الآخر، ورؤية العالم بطريقة الشخص

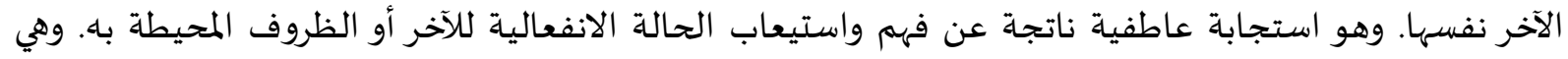

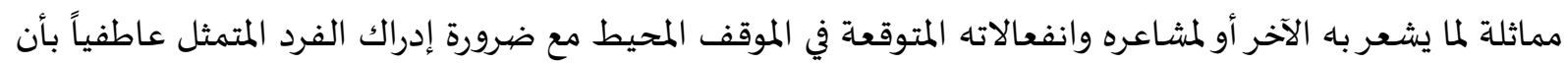

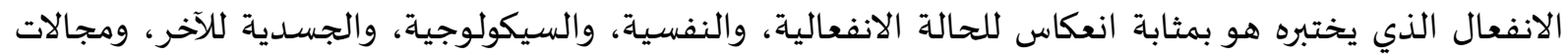

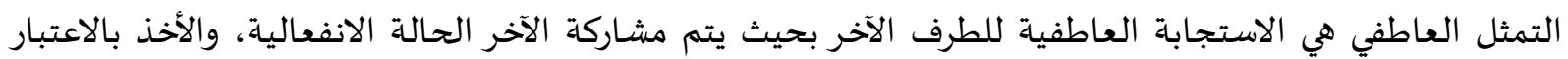

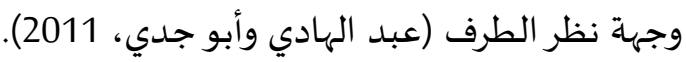

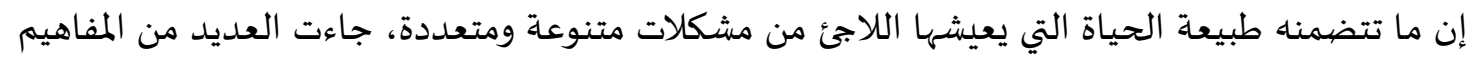

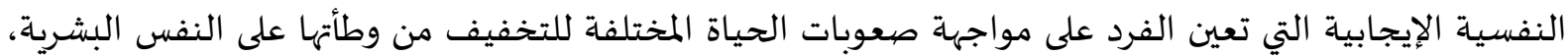

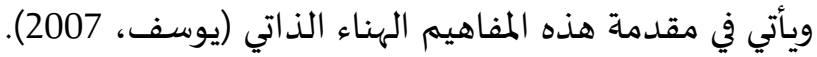

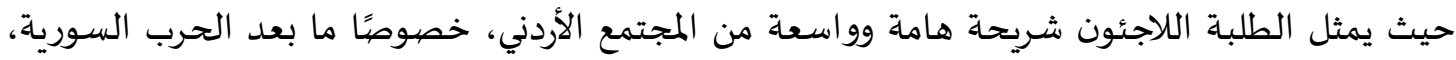

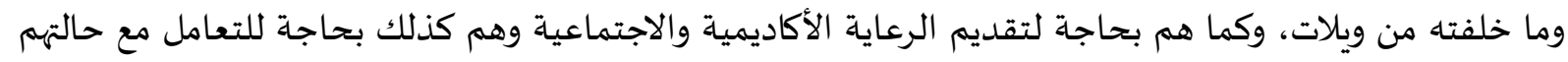

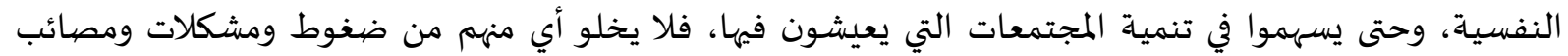

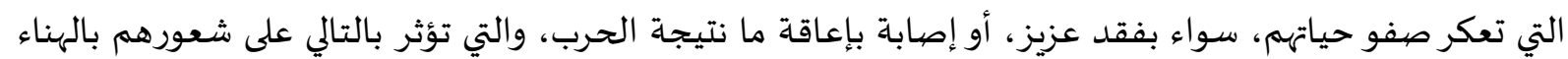
الذاتي، وتكيفهم واستقرارهم. ويُعد الهناء الذاتي مؤشراً على الحالة الصحية للفرد من النواحي الانفعالية والاجتماعية والنفسية، والهدف

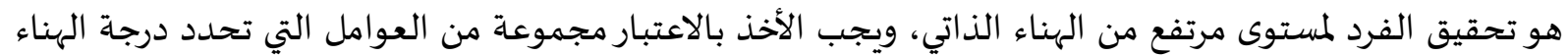

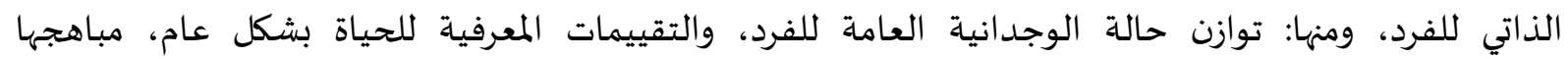
ومنغصاتها، ونوعية الحياة التي يعيشها الفرد، وتفاعلاته مع الآخرين، والعلاقات الاجتماعية والسمات الشخدية الشيكية

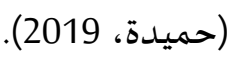

كما أن الهناء الذاتي يُعتبر جزءً من الصحة النفسية للفرد، وقد ارتبط كلاهما بالحياة الخيرة، والتي يسعى

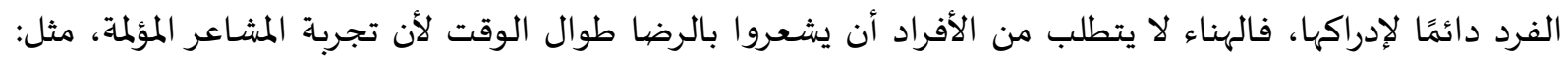

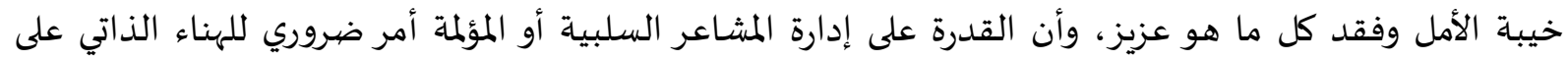
المدى البعيد (Malavia \& Punia, 2015). 
ويمثل الهناء الذاتي تقييمات متعددة الأبعاد، فالتقييم المعرفي يتضمن أحكام الفرد الواعية عن الرضا عن

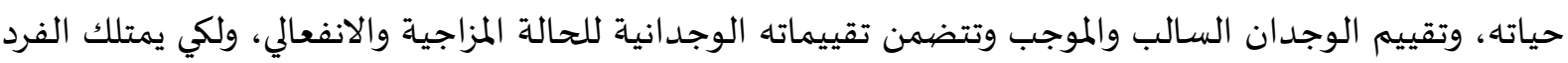

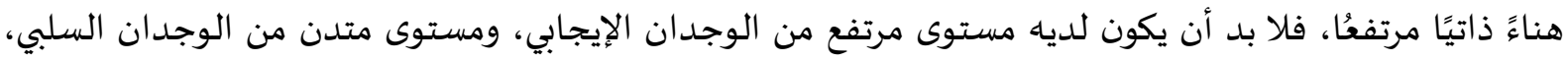

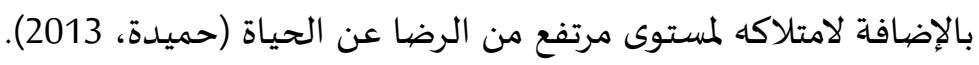

مشكلة الدراسة:

تشير بعض الإحصائيات إلى أن هناك ما يزيد عن (16) مليون إنسان يعيشون كلاجئين في دول العالم، وقد

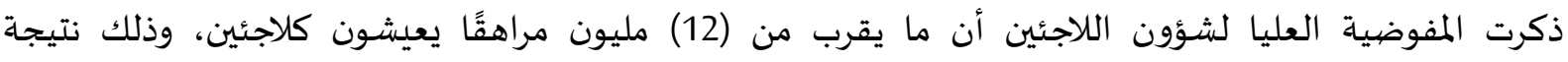
الاضطرار إلى ترك بلادهم الأصلية (ضمرة ونصار، 2014)، وتؤكد (مفوضية الأمم المتحدة لشؤون ألمون اللاجئين، 2013)

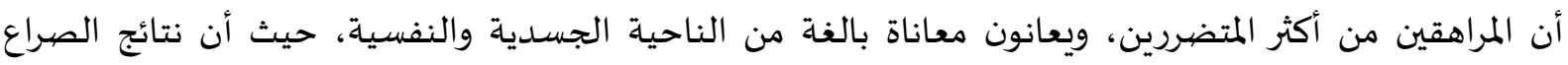

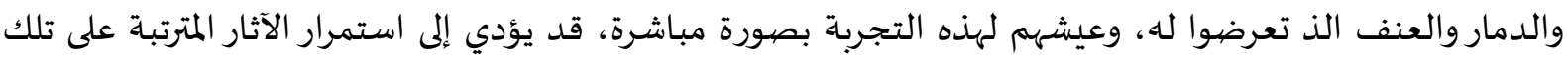

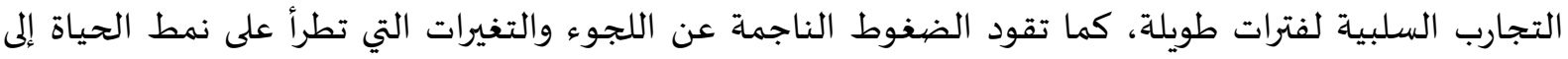
شعورهم بالانسحاب والعزلة عن المجتمع الجديد.

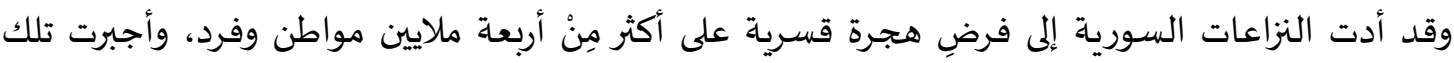

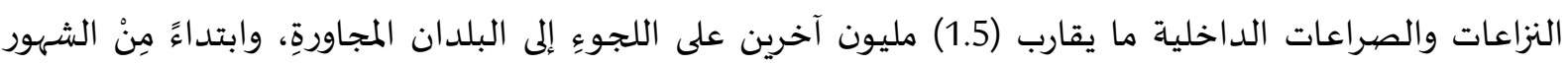

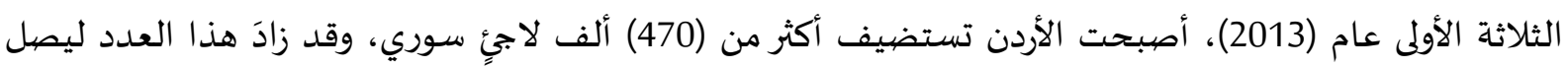

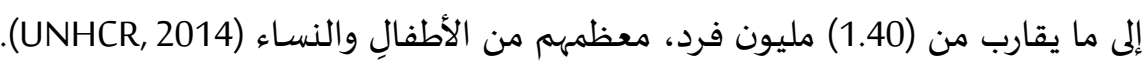

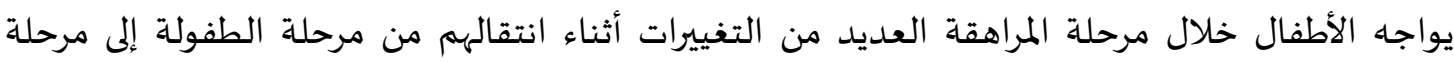

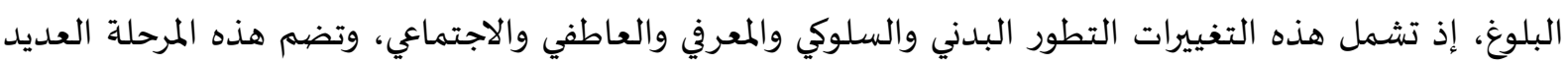

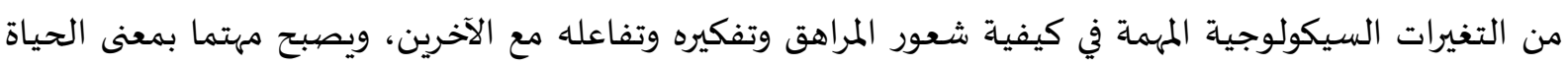

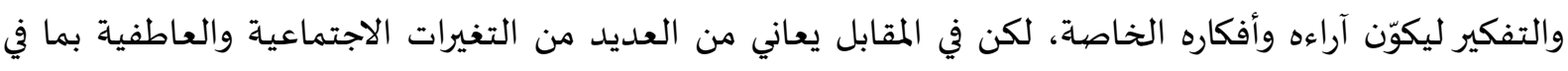

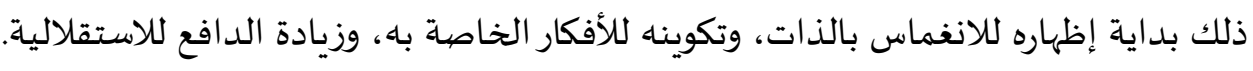

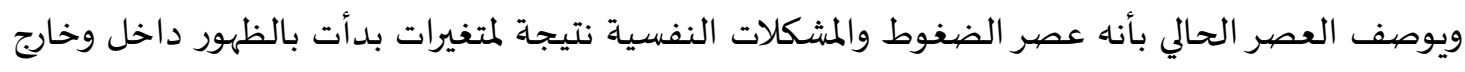

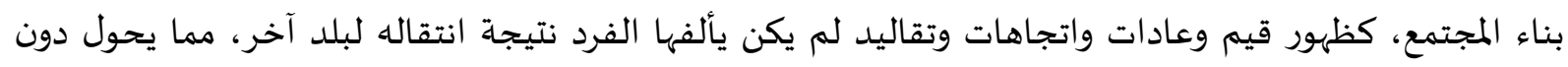

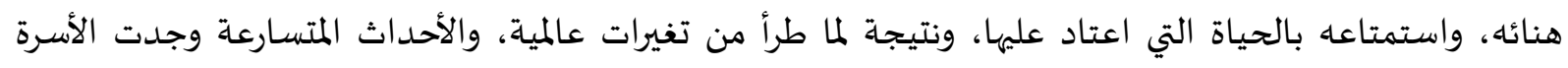

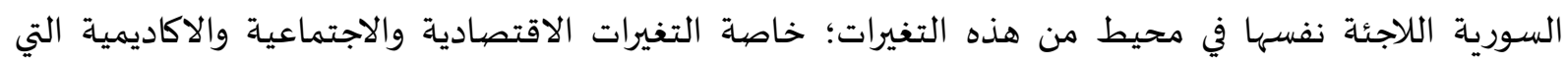

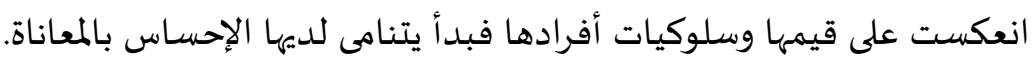

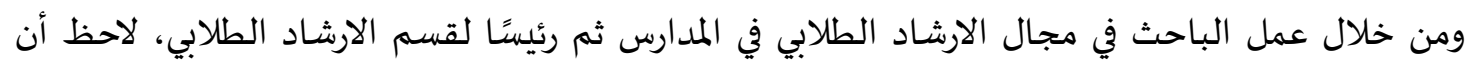

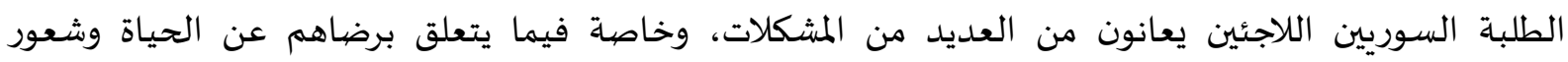

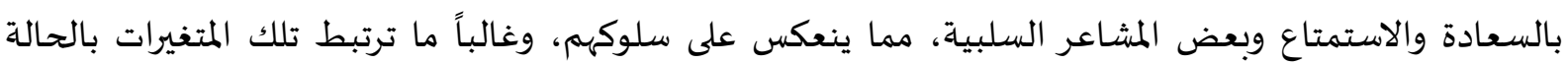

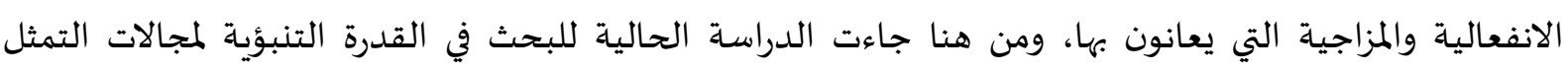

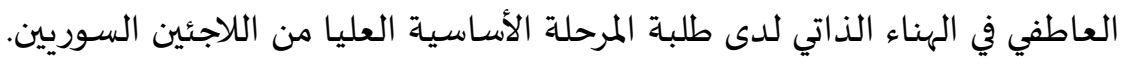


1- ما مستوى التمثل العاطفي لدى طلبة المرحلة الأساسية العليا من اللاجئين السوريين في مدارس مديرية

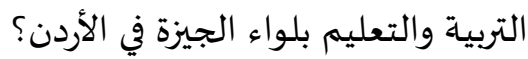
2- ما مستوى الهناء الذاتي لدى طلبة المرحلة الأسـاسية العليا من اللاجئين السوريين في مدارس مديرية التربية

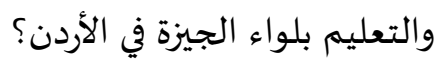
3- هل توجد علاقة ارتباطيه ذات دلالة إحصائية عند مستوى (Q>0.05) بين التمثل العاطفي والهناء الذاتي

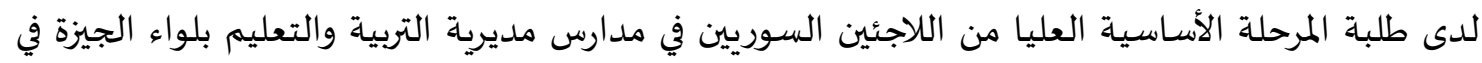

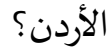
4- ما القدرة التنبؤية لمجالات التمثل العاطفي في الهناء الذاتي لدى طلبة المرحلة الأساسية العليا من اللاجئين

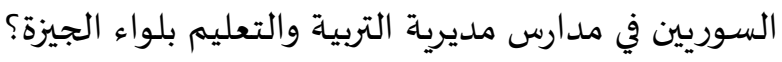

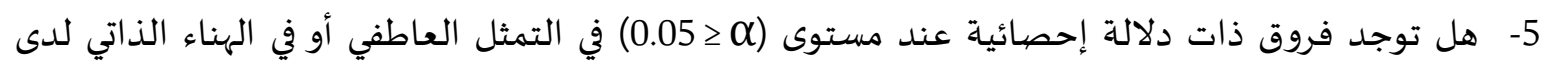

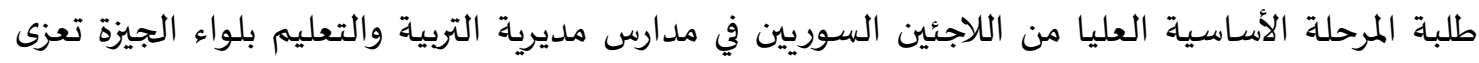

1. الكشف عن مستوى كل من التمثل العاطفي والهناء الذاتي لدى طلبة المرحلة الأساسية العليا من اللاجئين السوريين في مدارس مديرية التربية والتعليم بلواء الجيزة. 2. الكشف عن العلاقة بين التمثل العاطفي والهناء الذاتي لدى طلبة المرحلة الأساسية العليا من اللاجئين السوريين في مدارس مديرية التربية والتعليم بلواء الجيزة.

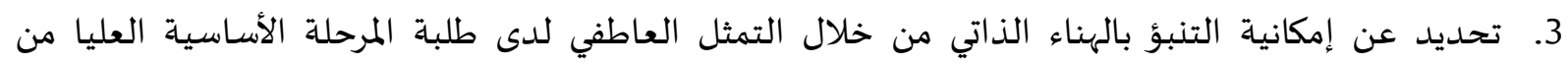
اللاجئين السوريين في مدارس مديرية التربية والتعليم بلواء الجيزة.

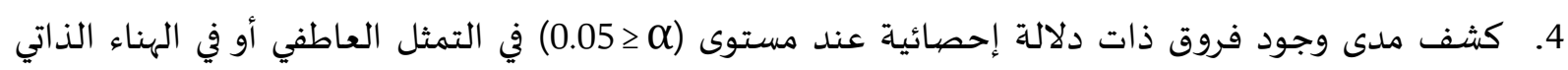

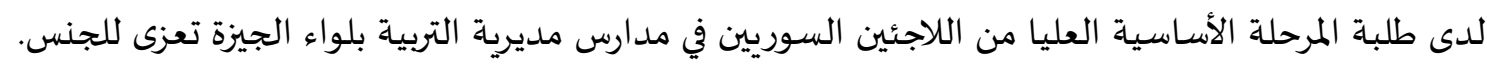

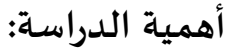

تبرز أهمية الدّراسة من أهمية العينة التي لها ظروفها واحتياجاتها الخاصة، وتبرز الأهمية من خِلالِ جَانبينِ رَيَيسِينِ هُمَمَا: الأهمية النظرية: حيث تكمن هذه الأهمية انطلاقًا من الفئة التي استهدفتها، والمتمثلة بالطلبة اللاجئين في

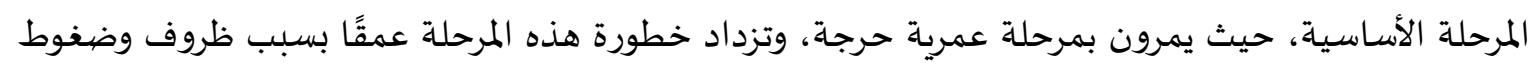

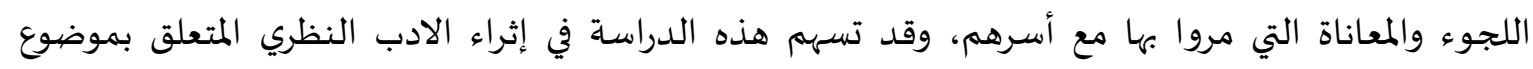

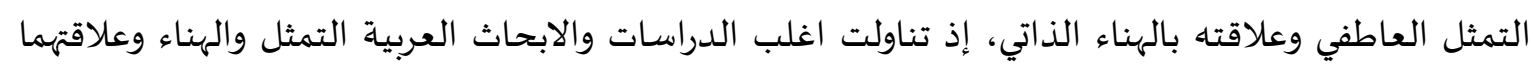

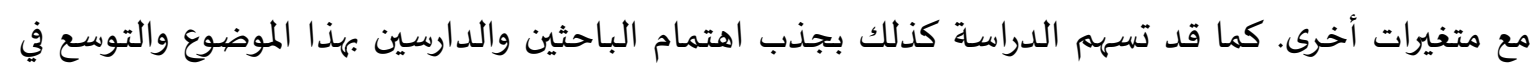
دراسته مستقبلاً، وذلك بربطه مع متغيرات أخرى لدى دارسي اللجوء غير تلك التي تم تناولها في هذه الدراسـة.

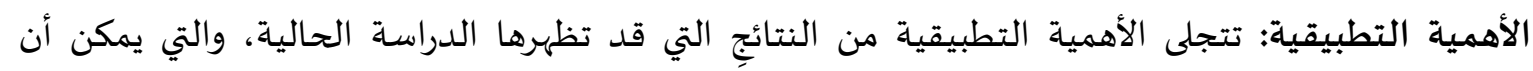

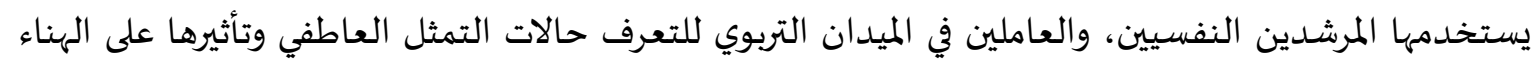

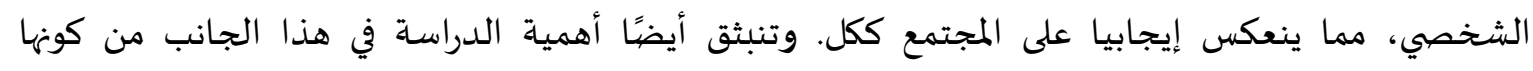


ستساعد المهتمين وصناع القرار في وضع أسس وتعليمات من شأنها تكوين شخصية سوية الطالب، والاستفادةٍ

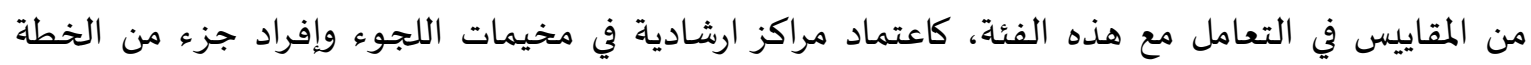

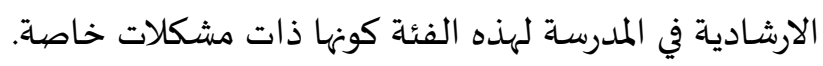

مصطلحات الدراسة:

- التمثل العاطفي: ويعرف بأنه القدرة على فهم اهتمامات الآخرين، والشعور بها، بحيث يصبح الفرد أكثر

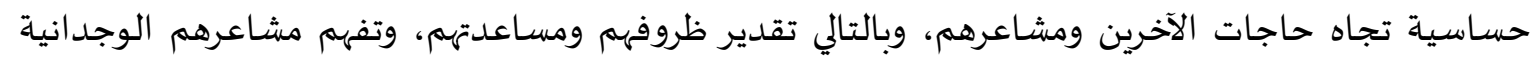

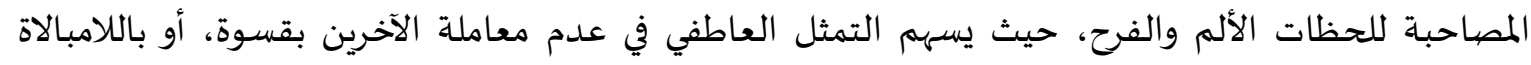

$$
\text { وعدم التقدير لمشاعرهم (سلامي، 2016). }
$$

- الهناء الذاتي: يعرف بأنه عبارة عن الإحساس بالسعادة الدائم نسبيًا داخل إطار الأسرة الذي يرجع في كثير من

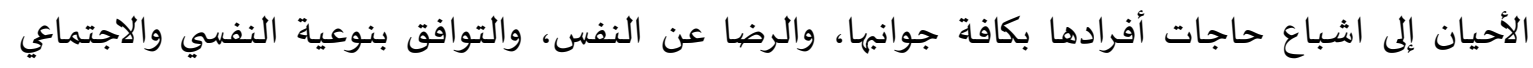

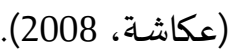

O م ويعرف إجرائياً بالدرجة التي يحصل عليها الطالب على المقياس الذي أعد لأغراض هذه الدراسة.

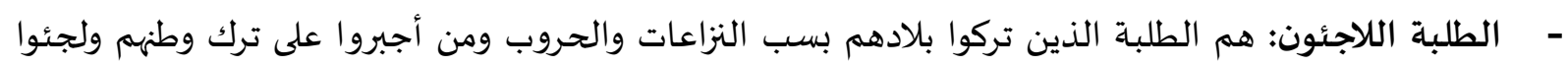

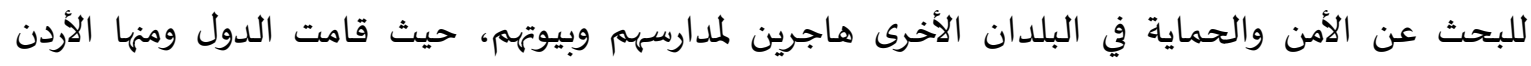

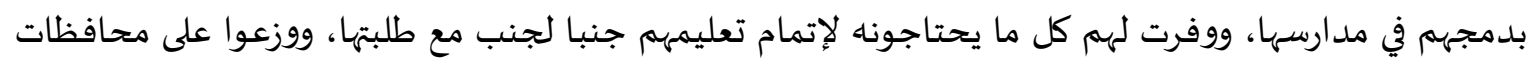
المملكة، وخصت هذه الدراسة منطقة الجيزة في جنوب العاصيمة عمان.

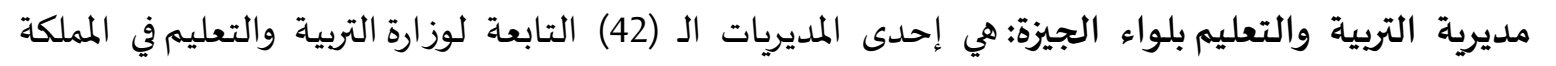
الأردنية الهاشمية، والتي تغطي منطقة لواء الجيزة، وتقع جنوب العاصيمة عمان وتبعد عنها مسافة (20كم).

2- 2 الإطار النظري والدراسـات السابقة. يعرف التمثل العاطفي بأنه دخول الفرد إلى العالم الإدراكي لفرد آخر، والنظور إلى العالم بنفس الطريقة

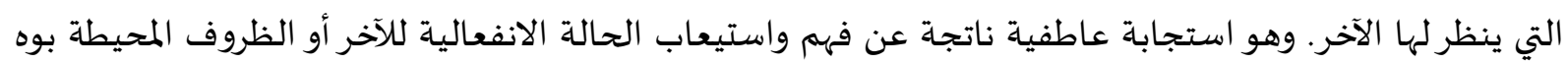
(عثمان، 2009).

ويرى جوليف وفارينجتون (Jolliff \& Farrington, 2009) بأن التمثل العاطفي سمة انفعالية تسهل تجربة

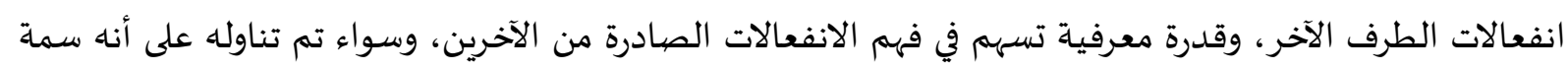

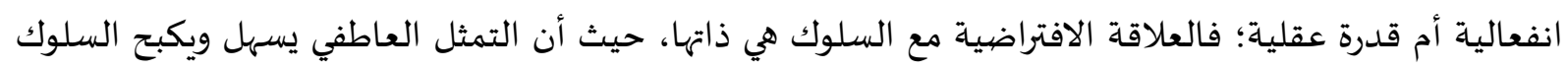
غير المقبول اجتماعيًا.

كما يعرف على أنه "قدرة الفرد على شعور الشخص وشعور الآخرين، وتحفيز ذاته وإدارة مشاعره بشكل سليم، عند إنشائه لعلاقاته مع الآخرين ممن حوله" (العباجي، 2019: 199).

تطرقت شعبان (2020) إلى خمسة أبعاد فرعية للتمثل العاطفي وهي:

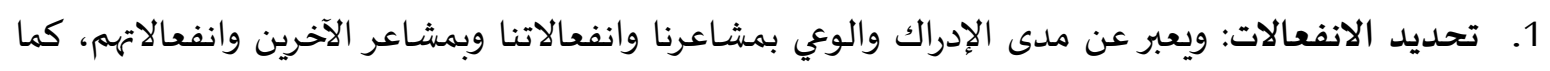

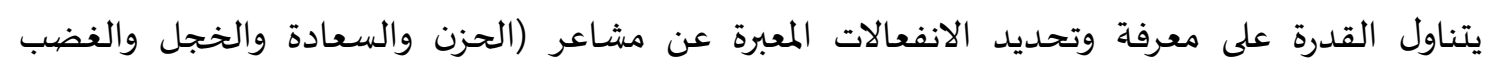
والخوف. 
2. الانفعالات المتعاكسة: وتعبر عن إدراك الفرد لانفعالات متعاكسة في موقف ما.

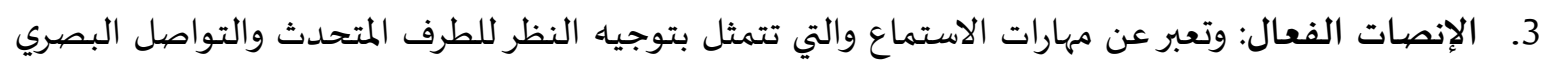

$$
\text { وعدم المقاطعة وإيماءات الرأس. }
$$

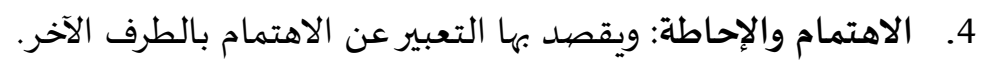

5. قبول الاختلاف: وتعبر عن إدراك التنوع والاختلاف للأفراد وتقبله، بالرغم من وجود أشياء مشتركة الآنياء بينهم.

الهناء الذاتي:

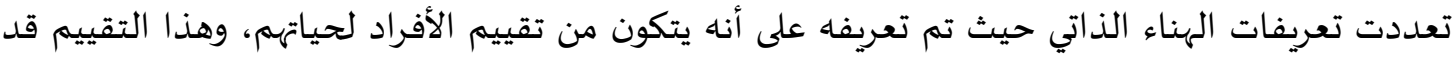

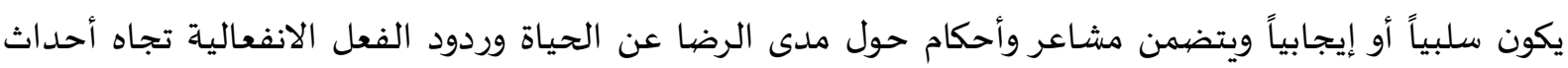
للحياة مثل الفرح والحزن (دياب، 2013) وقد أشار دينير (Diener, 2011) إلى أن مصطلح الهناء الذاتي ذو إطار شمولي يتضمن الرضا عن الحياة،

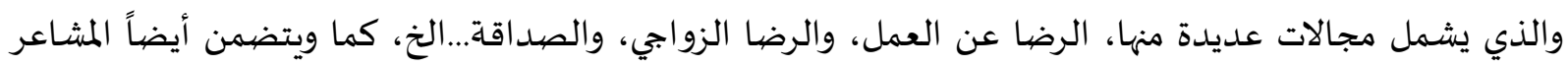

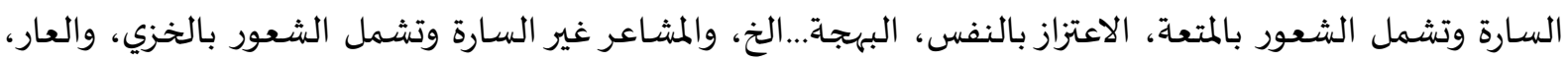

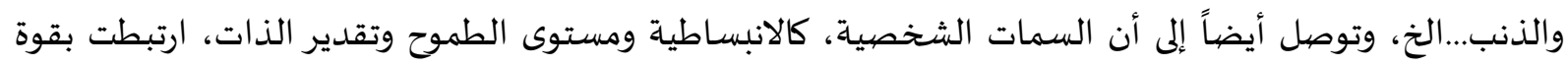

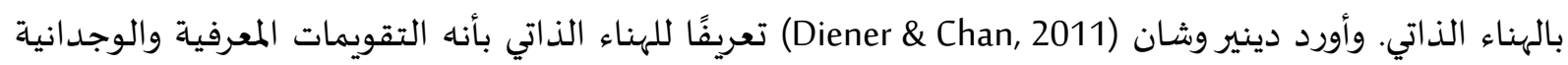

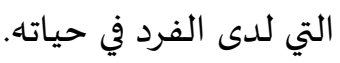

وقد عرفه الطيب والبهاص (2009) باعتباره حالة شعورية، وانعكاس للحالة الإيجابية المزاجية للفرد. كما

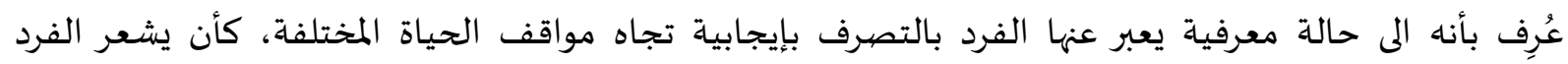

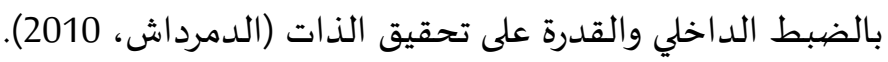

ثانياً - الدراسـات السابقة.

أ- دراسات متعلقة بالتمثل العاطفي: - أجرى وايد وآخرون ( Wied et al, 2006هدفت للتعرف على دور التمثل العاطفي في حل النزاع بين المراهقين،

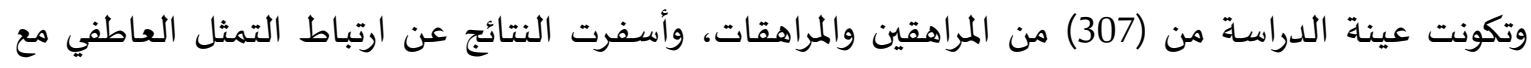

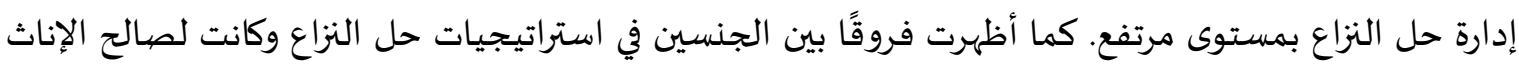

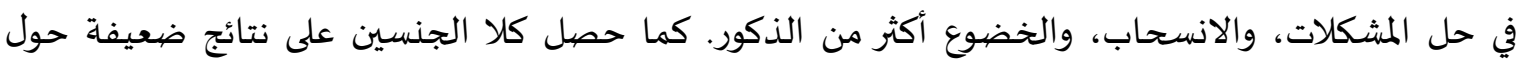
استراتيجياة الخضوع. - وأجرى عبد الهادي وأبو جدي (2011) دراسـة هدفت إلى تعرف قدرة التمثل العاطفي على التنبؤ بسلوك حل

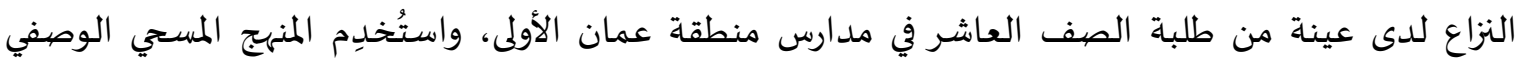

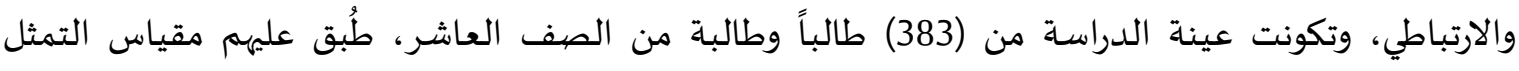

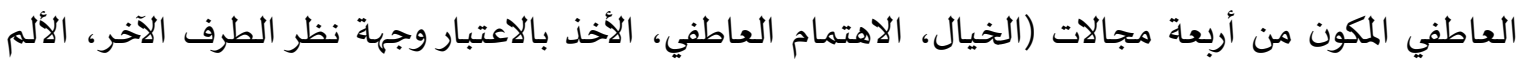

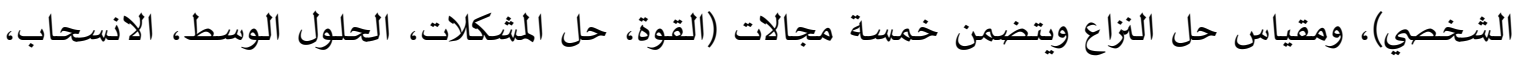

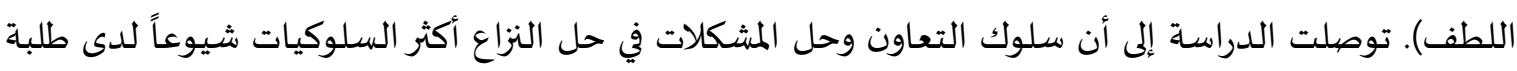

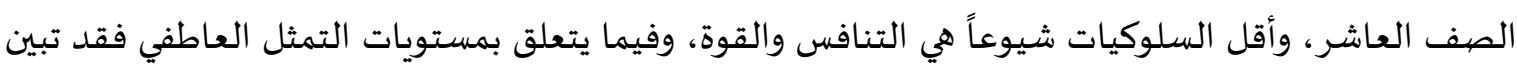

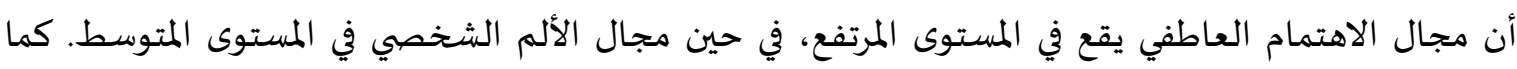




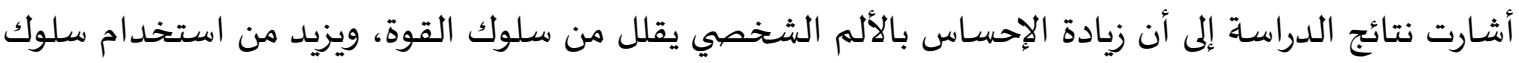

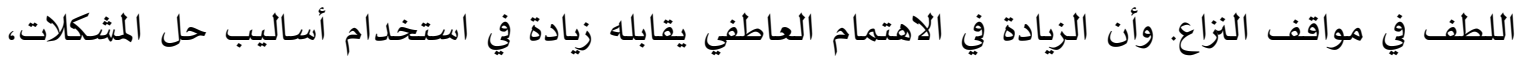

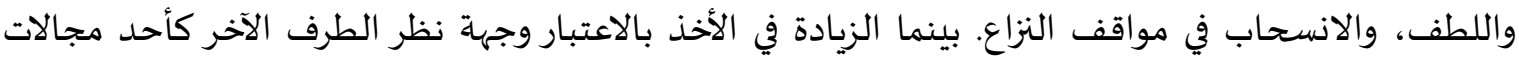

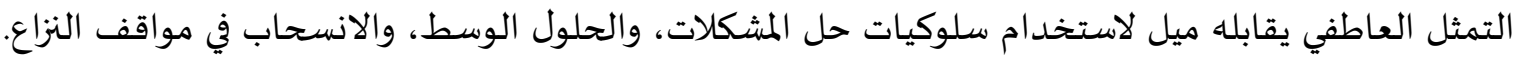

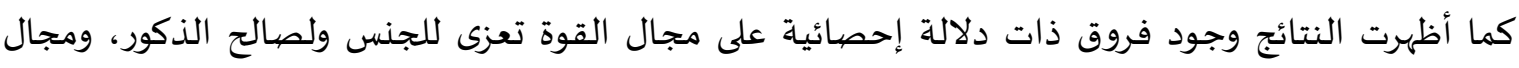
الخيال والألم الشخصي ولصالح الإناث. كما أجرى عبد الهادي والبسطامي (Abdel Hadi, 2017) دراسة هدفت الكشف عن قدرة يقظة الذّهِن على الئل

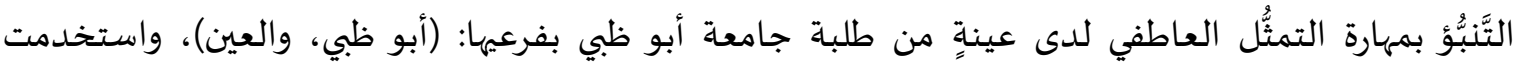

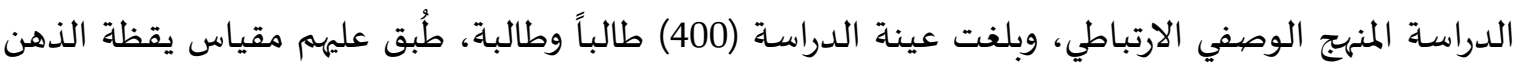

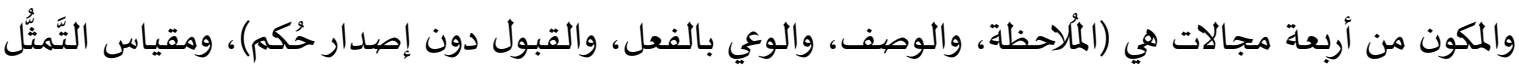

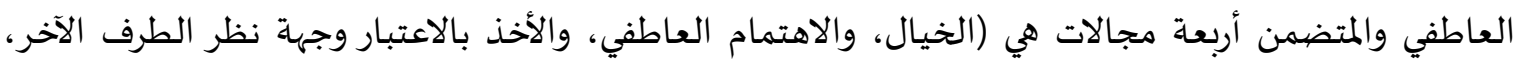

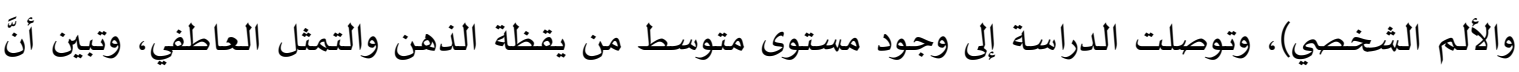

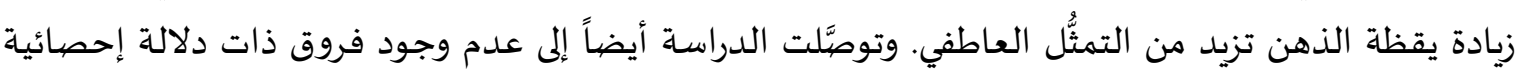

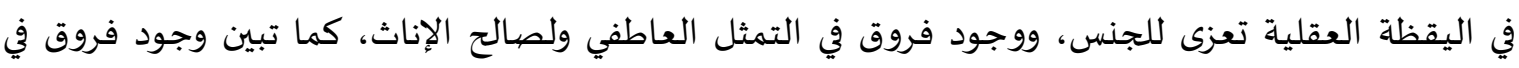

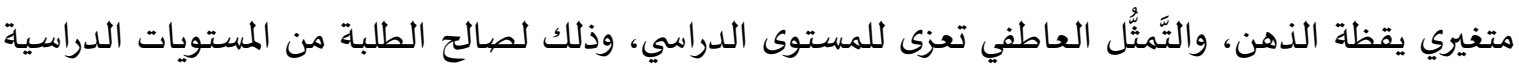
العُليا وبشكل تتابعي مقارنة بالطلبة من المستويات الدراسية الدُّنيا. كما أجرى الشواوره (2017) دراسة هدفت التعرف على مستوى الذكاء الاخلاقي والتمثل العاطفي، والعلاقة

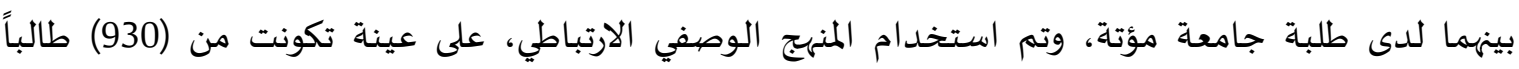

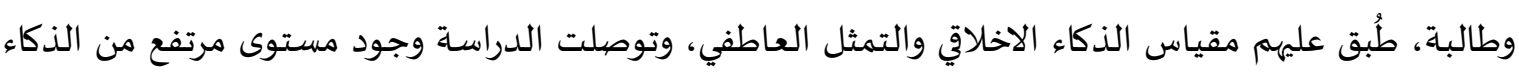
الاخلاقي والتمثل العاطفي لدى الطلبة، ووجود علاقة ارتباطية إيجابية ودالة احصائيا بين الذكاء الاخلاقي

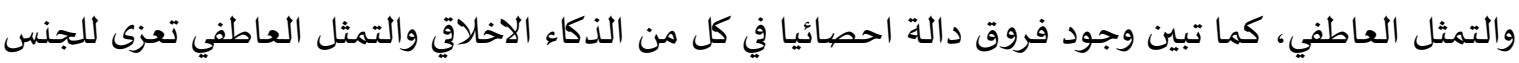
ولصالح الإناث.

ب- دراسات متعلقة بالهناء الذاتي:

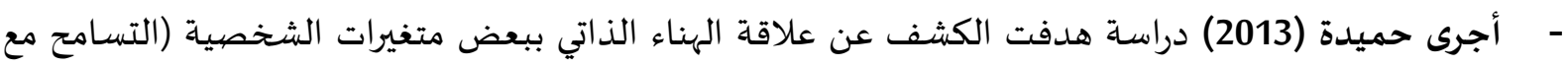
الذات، والرجاء، والتعاطف، وتقدير الذات) لدي طلاب الجامعة، وتم استخدام المنهج الوصفي التحليلي،

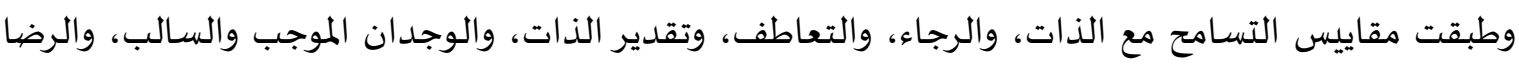

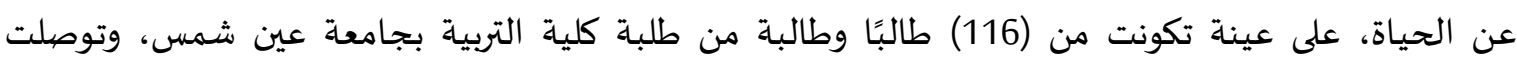

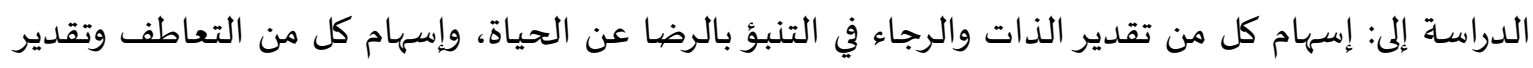

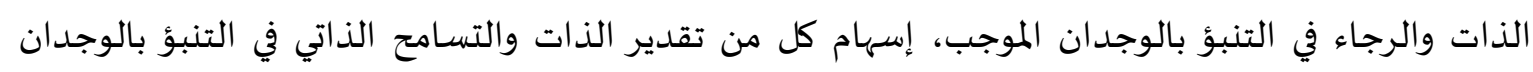

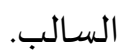
وهدفت دراسة فاليكين وجابريلافيكيوت (Valickiene \& Gabrialaviciute, 2015) إلى دراسة مؤشرات الهناء

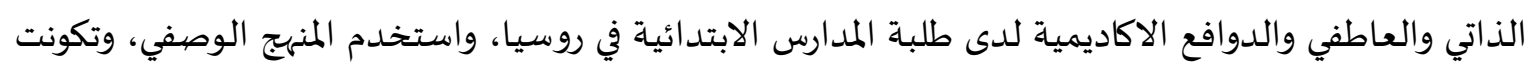

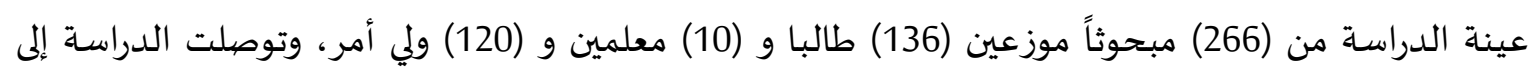


أن الدوافع الاكاديمية والتعاطف يؤثر على تكيف الطفل الاجتماعي وأداءه الاكاديمي، الأمر الذي يؤدي إلى تأثر الهناء الذاتي داخل المدرسة. وأجرى أكوايي وآخرون (Acuaye et al, 2018) دراسة هدفت إلى معرفة العلاقة بين تجارب الحروب واضطراب

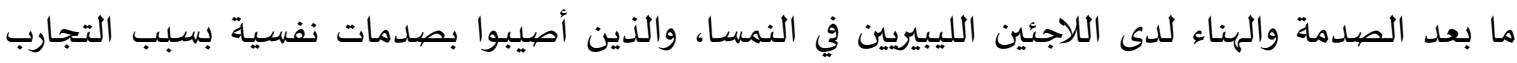

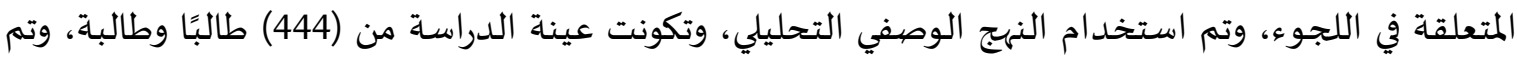

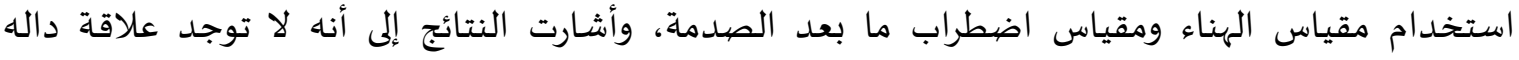
احصائيًا بين الهناء والتجارب المتعلقة بالحروب، وإلى عدم وجود فروق ذيناء دلاهي الله احصائية في مستوى الهناء تبعا لمتغير الجنس. وقام الخطيب والقرعان (2020) بدراسة هدفت إلى الكشف عن مستوى الهناء الذاتي وعلاقته بالطموح

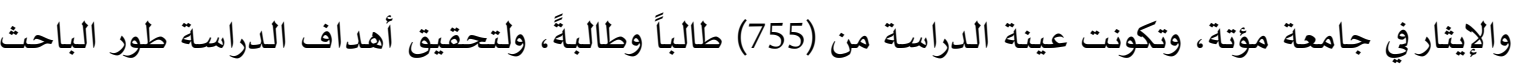

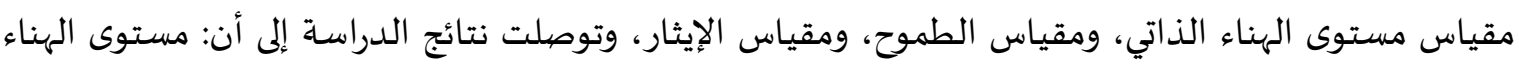

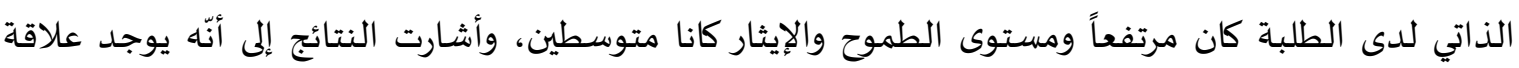

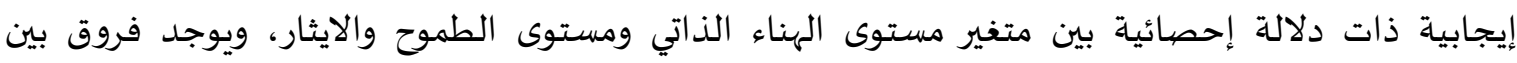
المتوسطات الحسابية في مستوى الهناء الذاتي تعزى للنوع الاجتماعي لصالح الـين الذكور.

التعقيب على الدراسات السابقة يلاحظ من متابعة الدراسات السابقة أن منها ما تناول التمثل العاطفي وقدرته التنبؤية ببعض المتابل المتغيرات

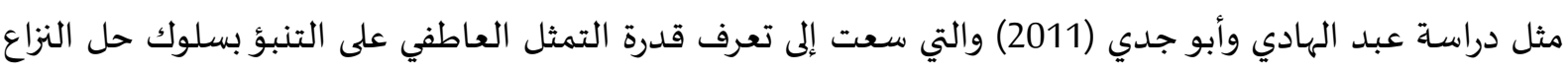

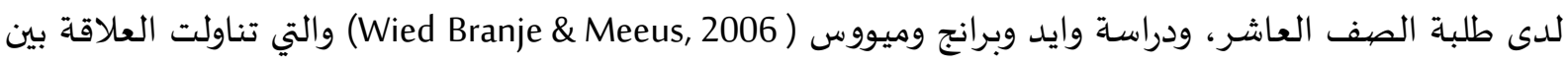

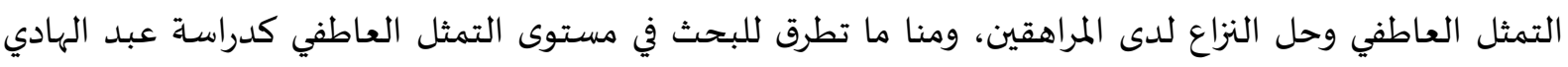

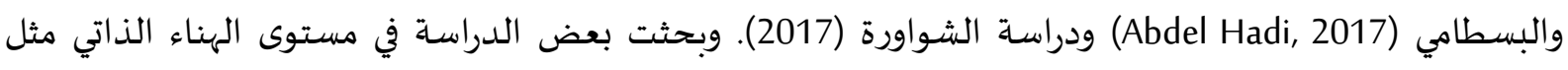
دراسة الخطيب والقرعان (2020) والتي حولت الكشف عن مستوى الهناء الذاتي وعلاقته بمستوى الطموح، ومن

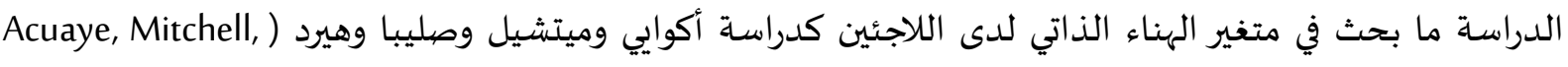

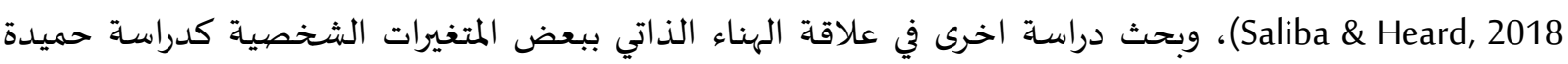

وتتشابه الدراسـة الحالية مع الدراسـات السابقة من حيث المنهج المستخدم وهو المنهج الارتباطي، وتحديداً المنهج التنبؤي في بعض الدراسات، وكذلك أنها استخدمت العينة واستخدامها الاستبانات والمقاييس.

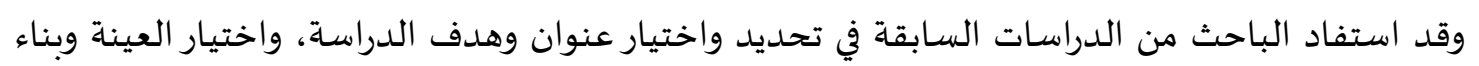
الادوات والمقايس، وتحديد المعالجات الاحصائية المناسبة، والتعليق على النتائج.

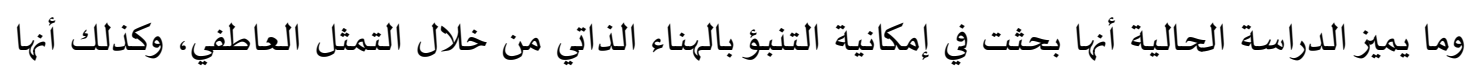
اجريت على الطلبة المراهقين من اللاجئين السوريين. 
اتبعت هذه الدراسة المنهج الوصفي التنبؤي بشقيه التحليلي والارتباطي، وضمن هذا المنهج تم استخدام المقاييس الخاصة بالدراسة التي تم تطبيقها على عينة من الطلبة السوريين اللاجئين في مدارس منطقة الجيزة،

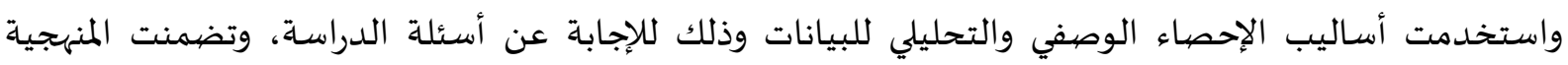

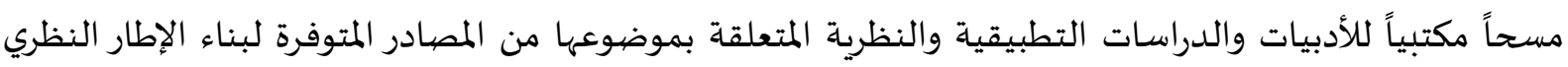
للدراسة.

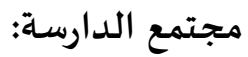

تكون مجتمع الدراسة من جميع الطلبة السوريين اللاجئين في مدارس مديرية التربية والتعليم بمنطقة

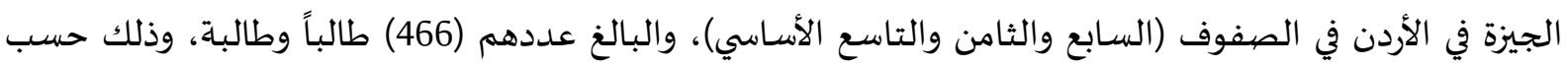
إحصائيات مديرية التربية والتعليم لقصبة الكرك، خلال الفصل الأول للعام الدراسي

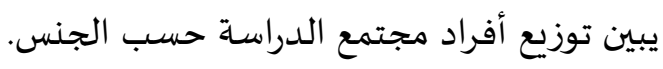

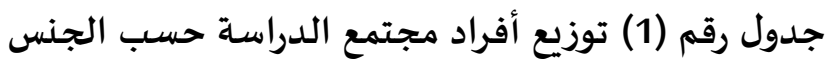

\begin{tabular}{|c|c|c|}
\hline النسبة المئوية & العدد & النوع الاجتمايي \\
\hline$\% 61.6$ & 287 & ذكور \\
\hline$\% 38.4$ & 179 & إناث \\
\hline$\% 100$ & 466 & المجموع \\
\hline
\end{tabular}

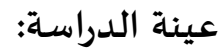
لأغراض الدراسة تم اختيار العينة بالطريقة الطبقية العشوائية، وكانت وحدة الاختيار المدرسة، تكونت من (185) طالباً وطالبة، شكلوا ما نسبته (40\%) من إجمالي أفراد مجتمع الدراسة، منهم (117) من الذكور، و (68) من

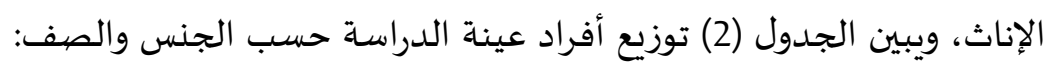

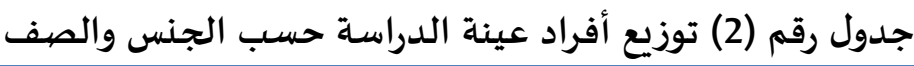

\begin{tabular}{|c|c|c|c|}
\hline النسبة المئوية & العدد & فئة المتغير & المتغير \\
\hline$\% 63.2$ & 116 & ذكور & \multirow{3}{*}{ الجنس } \\
\hline$\% 36.8$ & 69 & إناث & \\
\hline$\% 100$ & 185 & المجموع & \\
\hline$\% 35.2$ & 65 & السـابع & \multirow{4}{*}{ الصف } \\
\hline$\% 34.0$ & 63 & الثامن & \\
\hline$\% 30.8$ & 57 & التاسع & \\
\hline$\% 100$ & 185 & المجموع & \\
\hline
\end{tabular}

أداتي الدراسـة

لجمع البيانات المتعلقة بالدراسة اشتملت الدراسة على مقياسين هما: 
أولاًا مقياس التمثل العاطفي: تم استخدام مقياس التمثل العاطفي في دراسة (عبد الهادي وأبو جدي، 2011)، وقد تكون المقياس من (28) فقرة تتوزع على (4) مجالات وهي: بعد الخيال: وتمثله (7) فقرات، وبعد الاهتمام العاطفي: وتمثله (7) فقرات

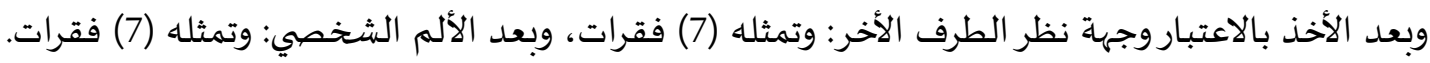

\section{الصبدق الظاهري لمقياس التمثل العاطفي:}

تم التحقق من صدق المقياس باستخدام الصددق الظاهري وذلك بعرضيه بصورته الأولية على (10) من

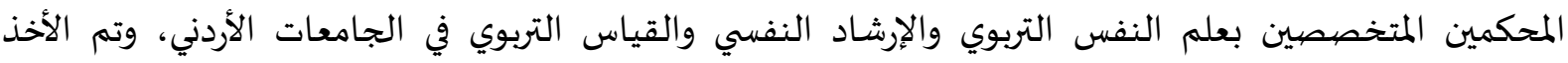

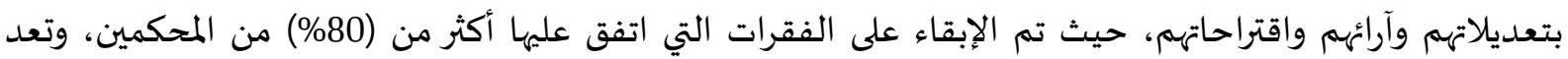

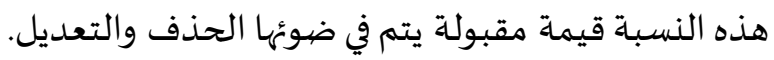

صدق البناء الداخلي لمقياس التمثل العاطفي:

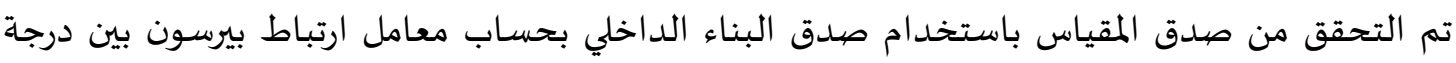
الفقرة والدرجة الكلية على البعد الذي تنتمي إليه على عينة استطلاعية بلغت (34) طالباً وطالبة تم اختيارهم

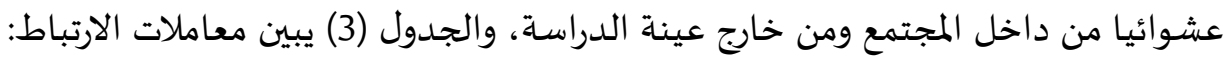
جدول (3) صدق البناء الداخلي لمقياس التمثل العاطفي والدول

\begin{tabular}{|c|c|c|c|c|c|c|c|}
\hline الارتباط معامل & الفقرة & 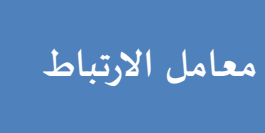 & رقم الفقرة & الارتباط معامل & رقم الفقرة & معامل الارتباط & الفقرة رقم \\
\hline \multicolumn{2}{|c|}{ الألم الشخصي } & \multicolumn{2}{|c|}{ الأخذ بالاعتباروجهة نظر الطرف الأخر } & \multicolumn{2}{|c|}{ الاهتمام العاطفي } & \multicolumn{2}{|c|}{ الخيال } \\
\hline $.595^{* *}$ & 22 & $.709^{* *}$ & 15 & $.624^{* *}$ & 8 & $.594^{* *}$ & 1 \\
\hline $.653^{* *}$ & 23 & $.635^{* *}$ & 16 & $.377^{* *}$ & 9 & $.411^{*}$ & 2 \\
\hline $.525^{* *}$ & 24 & $.719^{* *}$ & 17 & $.561^{* *}$ & 10 & $.496^{* *}$ & 3 \\
\hline $.637^{* *}$ & 25 & $.481^{* *}$ & 18 & $.384^{*}$ & 11 & $.375^{*}$ & 4 \\
\hline $.389^{*}$ & 26 & $.703^{* *}$ & 19 & $.358^{*}$ & 12 & $.561^{* *}$ & 5 \\
\hline $.396^{*}$ & 27 & $.427^{*}$ & 20 & $.397^{*}$ & 13 & $.427^{*}$ & 6 \\
\hline $.637^{* *}$ & 28 & $.608^{* *}$ & 21 & $.649^{* *}$ & 14 & $.501^{* *}$ & 7 \\
\hline
\end{tabular}

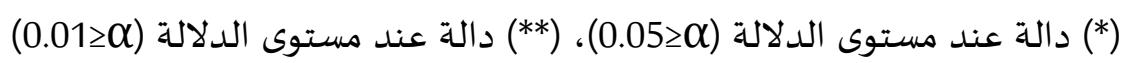

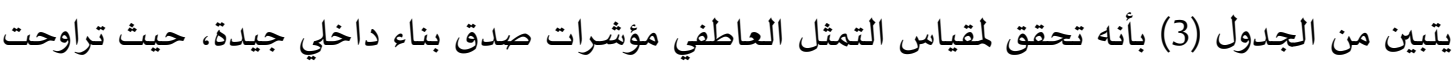

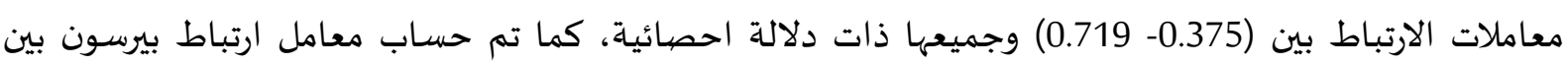

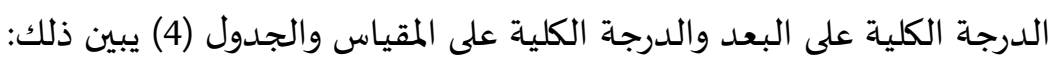
جدول (4) معامل الارتباط بين الدرجة الكلية على البعد والدرجة الكلية على مقياس التمثل العاطفي

\begin{tabular}{|c|c|}
\hline معامل الارتباط & 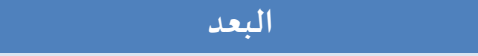 \\
\hline $.842^{* *}$ & الاهتمام العاطفي \\
\hline $.857^{* *}$ & الأخذ بالاعتباروجهة نظر الطرف الأخر \\
\hline $.814^{* *}$ & الألم الشخصي \\
\hline $.754^{* *}$ & ما وراء المعرفة \\
\hline
\end{tabular}




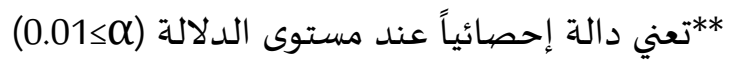

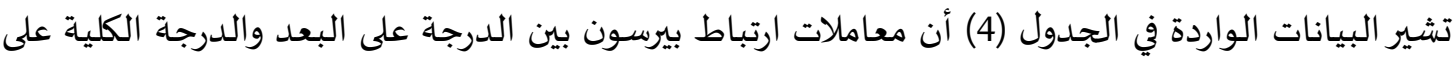

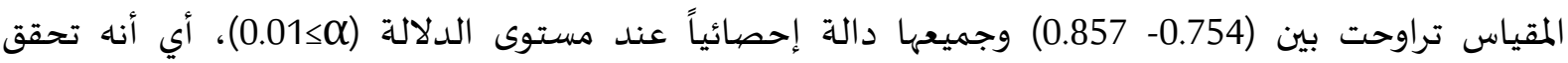
للمقياس دلالات صدق بناء جيدة.

\section{ثبات مقياس التمثل العاطفي:} تم التحقق من دلالات ثبات المقياس بطريقتين: الأولى باستخدام ثبات الإعادة (Test Retest)، حيث طبق التقات

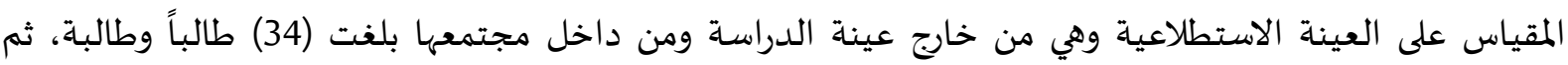

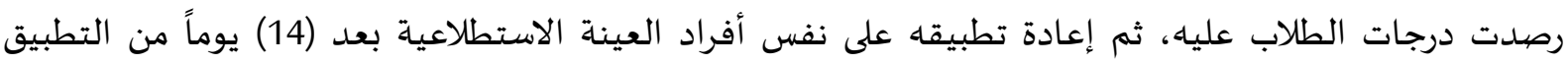

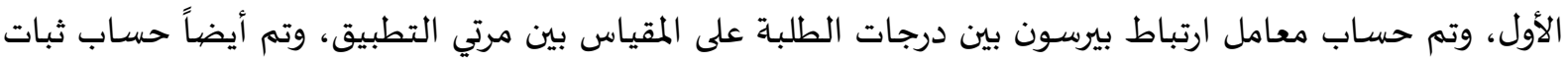

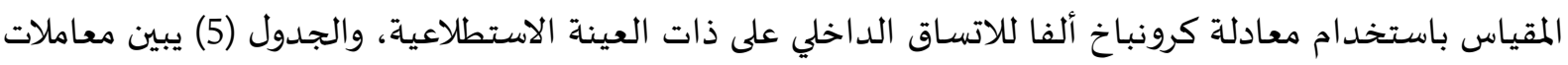

ثبات المقياس: جدول (5) معاملات ثبات مقياس التمثل العاطفي

\begin{tabular}{|c|c|c|}
\hline ثبات كرونباخ ألفا & 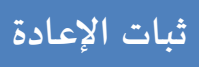 & 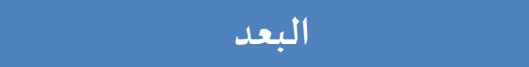 \\
\hline 0.85 & 0.83 & 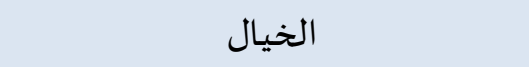 \\
\hline 0.84 & 0.81 & الاهتمام العاطفي \\
\hline 0.82 & 0.82 & الأخذ بالاعتباروجهة نظر الطرف الأخر \\
\hline 0.80 & 0.78 & الألم الشخصي \\
\hline 0.88 & 0.86 & 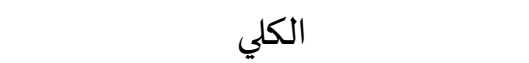 \\
\hline
\end{tabular}

يتبين من الجدول (5) أن معامل ثبات الاعادة لمقياس التمثل العاطفي ككل بلغ (0.86) وللأبعاد تراوح بين

(0.78- 0.83)، أما معامل ثبات كرونباخ الفا للمقياس ككل فقد بلغ (0.88) وللمجالات تراوح بين (0.80- 0.85).

\section{تصحيح مقياس التمثل العاطفي وتفسيره}

تتم الاستجابة على المقياس بحسب تدريج ليكرت الخماسي (دائماً، غالباً، أحياناً، نادراً، إطلاقاً)، وتعطى وتفي

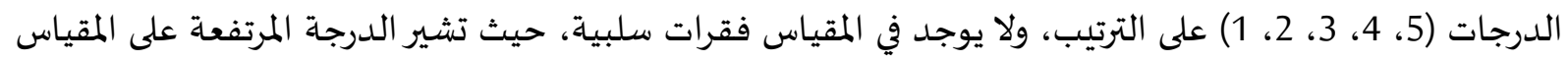
على مستوى مرتفع من التمثل العاطفي، ويتم الحكم على المستوى بالاعتماد على المعيار التالي:

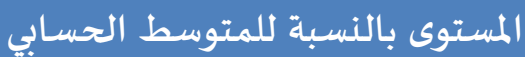

منخفض

متوسط

مرتفع

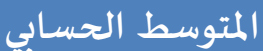

$1-2.33$

$2.34-3.67$

3.68 فما فوق

ثانياً- مقياس الهناء الذاتي:

تم تطوير مقياس الهناء الذاتي من خلال الاطلاع على المقاييس والدراسات السابقة مثل (أحمد، 2008)

ودراسة (أبو زيد، وعبد الرحمن وسعفان، 2019) و (الخطيب، 2020)، وتكون الاختبار بصورته النهائية من (36) 
فقرة، تتوزع على اربعة أبعاد وهي: الهناء الأسري: وتمثله (8) فقرات، والهناء الدراسي: وتمثله (9) فقرات، والعلاقات

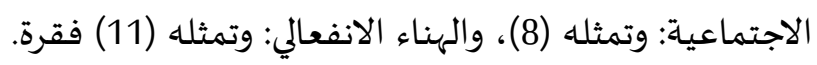

الصدق الظاهري لمقياس الهناء الذاتي: تم التحقق من صدق الاختبار باستخدام صدق المحكمين وذلك بعرضها بصورته الأولية على (10) من

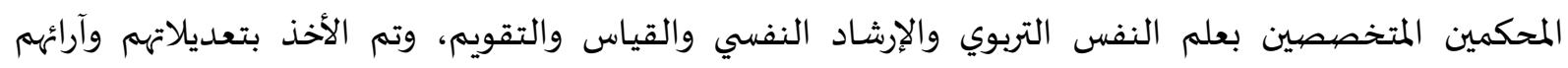

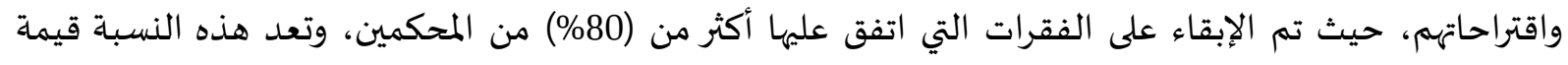

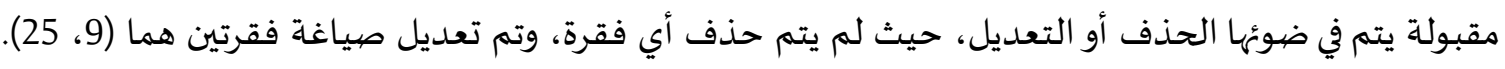

صدق البناء الداخلي لمقياس الهناء الذاتي: تم التحقق من صدق الاختبار باستخدام صدق البناء الداخلي بحساب معامل ارتباط بيرسون بين الفين الفقرة

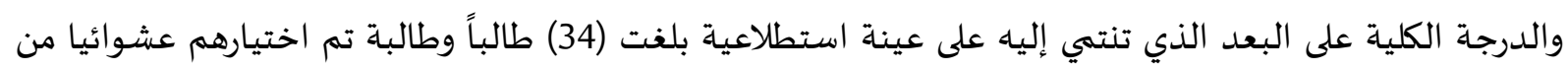

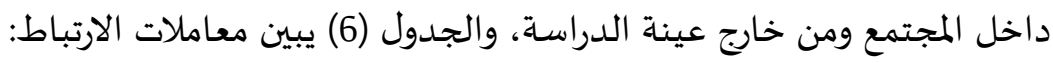

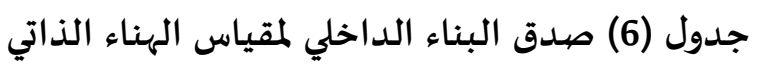

\begin{tabular}{|c|c|c|c|c|c|c|c|c|c|c|c|}
\hline معامل & الارتباط معامل & الفقرة & الارتباط معامل & الارتباط معامل & الفقرة & الارتباط معامل & معامل الارتباط & الفقرة & الارتباط معامل & الارتباط معامل & رقفم \\
\hline \multicolumn{3}{|c|}{ الانفعالي } & \multicolumn{3}{|c|}{ العلاقات الاجتماعية } & \multicolumn{3}{|c|}{ الدراسي } & \multicolumn{3}{|c|}{ الاسـري } \\
\hline $.555^{* *}$ & $.671^{* *}$ & 26 & $.361^{* *}$ & $.432^{* *}$ & 18 & $.524^{* *}$ & $.603^{* *}$ & 9 & $.437^{* *}$ & $.471^{* *}$ & 1 \\
\hline $.454^{* *}$ & $.542^{* *}$ & 27 & $.487^{* *}$ & $.555^{* *}$ & 19 & $.444^{* *}$ & $.491^{* *}$ & 10 & $.448^{* *}$ & $.590^{* *}$ & 2 \\
\hline $.354^{*}$ & $.374^{*}$ & 28 & $.447^{* *}$ & $.447^{* *}$ & 20 & $.438^{* *}$ & $.497^{* *}$ & 11 & $.432^{* *}$ & $.523^{* *}$ & 3 \\
\hline $.427^{* *}$ & $.495^{* *}$ & 29 & $.376^{* *}$ & $.458^{* *}$ & 21 & $.572^{* *}$ & $.572^{* *}$ & 12 & $.513^{* *}$ & $.513^{* *}$ & 4 \\
\hline $.491^{* *}$ & $.534^{* *}$ & 30 & $.357^{*}$ & $.361^{*}$ & 22 & $.437^{* *}$ & $.514^{* *}$ & 13 & $.415^{* *}$ & $.470^{* *}$ & 5 \\
\hline $.351^{*}$ & $.369^{*}$ & 31 & $.438^{* *}$ & $.519^{* *}$ & 23 & $.412^{*}$ & $.352^{*}$ & 14 & $.437^{* *}$ & $.492^{* *}$ & 6 \\
\hline $.507^{* *}$ & $.586^{* *}$ & 32 & $.592^{* *}$ & $.659^{* *}$ & 24 & $.583^{* *}$ & $.583^{* *}$ & 15 & $.523^{* *}$ & $.570^{* *}$ & 7 \\
\hline $.468^{* *}$ & $.547^{* *}$ & 33 & $.510^{* *}$ & $.582^{* *}$ & 25 & $.453^{* *}$ & $.544^{* *}$ & 16 & $.397^{* *}$ & $.397^{* *}$ & 8 \\
\hline $.539^{* *}$ & $.624^{* *}$ & 34 & & & & $.428^{* *}$ & $.484^{* *}$ & 17 & & & \\
\hline $.384^{* *}$ & $.445^{* *}$ & 35 & & & & & & & & & \\
\hline $.462^{* *}$ & $.537^{* *}$ & 36 & & & & & & & & & \\
\hline
\end{tabular}

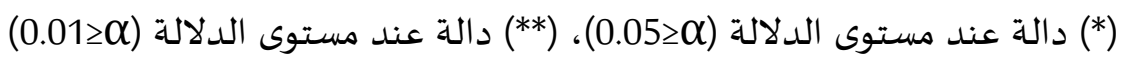

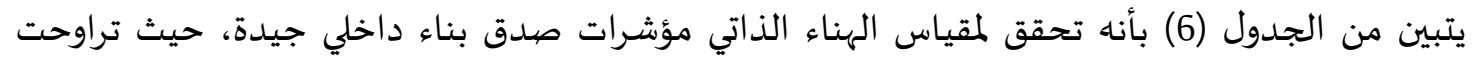

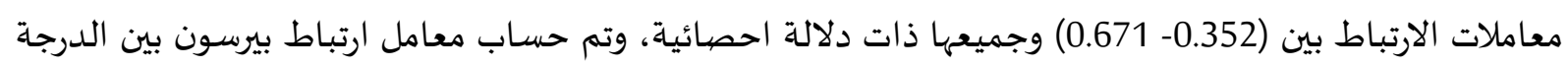
على البعد والدرجة الكلية على المقياس كما في الجدول (7) (7): جدول (7) معامل ارتباط بيرسون بين الدرجة على البعد والدرجة الكلية لمقياس الهناء الذاتئي

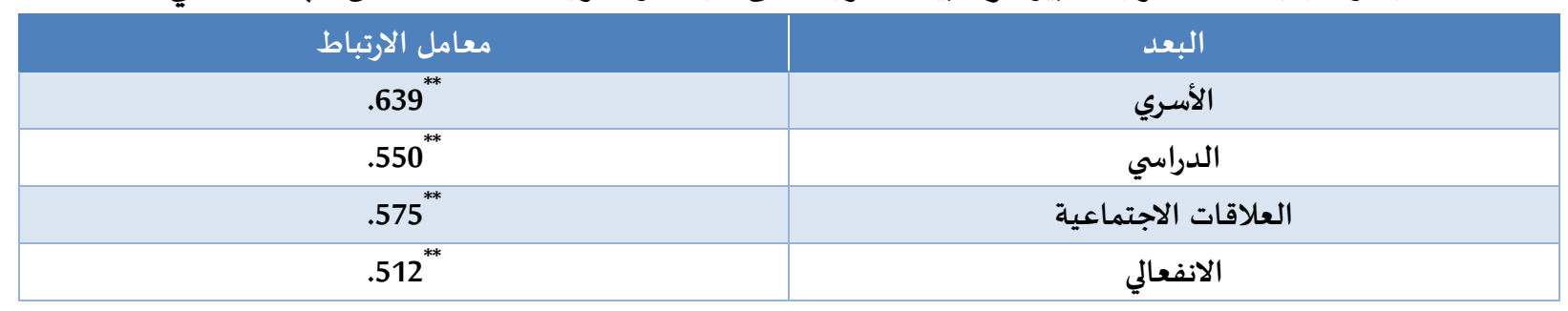




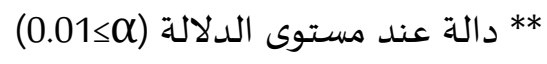

يلاحظ من الجدول (7) بأن معاملات الارتباط تراوحت بين (0.512- 0.639) وجميعها ذات دلالة احصائية

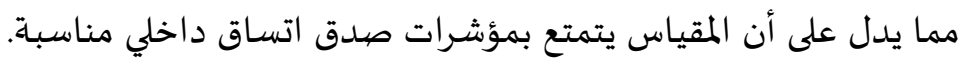

$$
\text { ثبات مقياس الهناء الذاتي }
$$

تم التحقق من دلالات ثبات باستخدام معادلة كرونباخ ألفا للاتساق الداخلي حيث طبق المقياس على

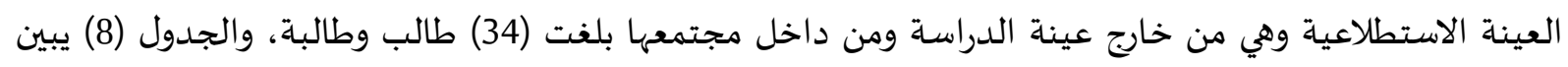

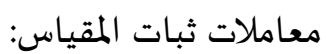
جدول (2) معاملات ثبات مقياس الهناء الذاتي

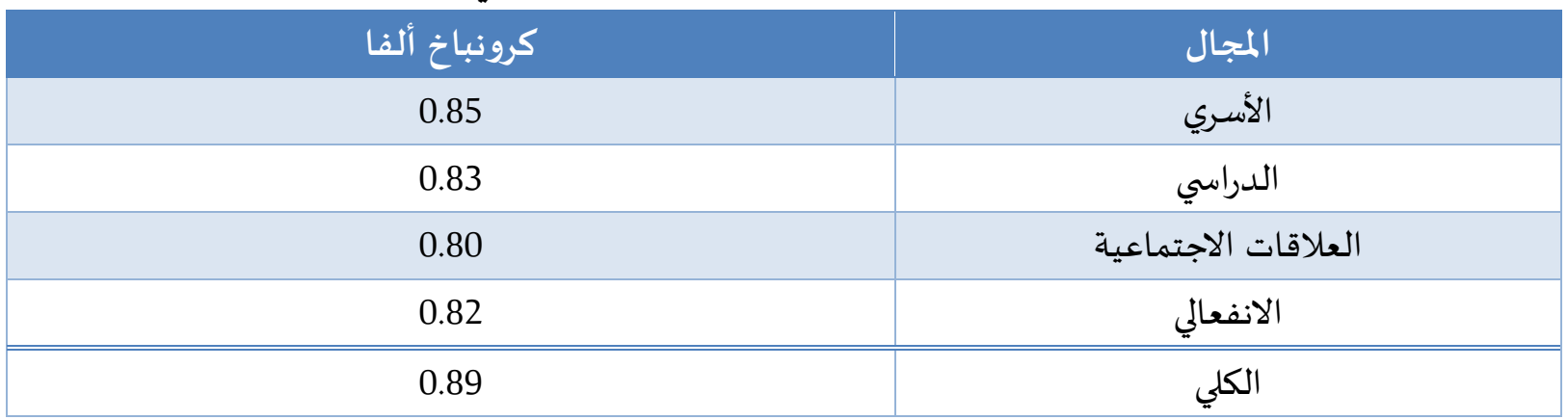

يتبين من الجدول (8)، ومعامل ثبات كرونباخ الفا للمقياس ككل بلغ (0.89) وللأبعاد تراوح بين (0.800.85) وهذه القيمة مقبولة لهذا المقياس. تصحيح مقياس الهناء الذاتي وتفسيره تتم الاستجابة على المقياس بحسب تدريج ليكرت الخماسي (دائماً، غالباً، احياناً، نادراً، اطلاقاً)، وتعطى التهاء

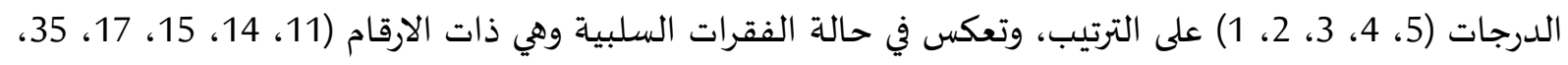

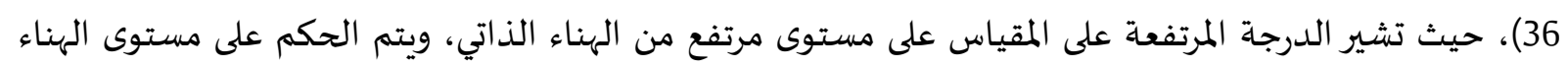

\begin{tabular}{|c|c|}
\hline المستوى بالنسبة للمتوسط الحسابي & المتوسط الحسابي \\
\hline منخفض & 1- 2.33 \\
\hline متوسط & $2.34-3.67$ \\
\hline مرتفع & 3.68فما فوق \\
\hline
\end{tabular}

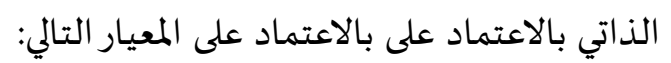

$$
\begin{aligned}
& \text { المعالجات الإحصائية } \\
& \text { للإجابة عن اسئلة الدراسة تم استخدام الإحصائيات التالية: }
\end{aligned}
$$

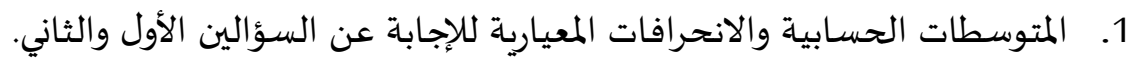

$$
\begin{aligned}
& \text { 2. معامل ارتباط بيرسون وتحليل الانحدار البسيط للإجابة عن السؤال الثالث. }
\end{aligned}
$$




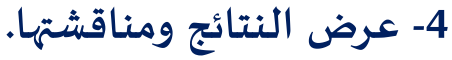

النتائج المتعلقة بالسؤال الأول: ما مستوى التمثل العاطفي لدى طلبة المرحلة الأسساسية العليا في مدارس مديرية التربية والتعليم بلواء الجيزة في الأردن؟ وللإجابة على السؤال تم حساب المتوسطات الحسابية والانحرافات المعيارية، والجدول (9) يبين ذلك جدول (9) المتوسطات الحسابية والانحرافات المعيارية لمستوى التمثل العاطفي لدى الطلبة اللاجئين السوريين في مدارس مديرية تربية وتعليم الجيزة في الأردن مرتبة تنازليا بحسب المتوسطات

\begin{tabular}{|c|c|c|c|c|c|}
\hline المستوى & 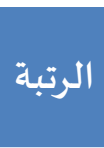 & الالمحراف & الحستوسط & البعد & 个 \\
\hline متوسط & 1 & .59 & 3.44 & الاهتمام العاطفي & 2 \\
\hline متوسط & 2 & .62 & 3.39 & الأخذ بالاعتباروجهة نظر الطرف الأخر & 3 \\
\hline متوسط & 3 & .72 & 3.37 & الخيال & 1 \\
\hline متوسط & 4 & .65 & 3.32 & الألم الشخصي & 4 \\
\hline متوسط & - & .52 & 3.38 & الكلي & \\
\hline
\end{tabular}

يلاحظ من خلال الجدول (9) أن مستوى التمثل العاطفي لدى عينة من الطلبة اللاجئين السوريين في مدارس مديرية تربية وتعليم الجيزة في الأردن جاء متوسطاً إذ جاء متوسطه الحسابي (3.38) وانحرافه معياري (0.52)، وقد جاء بعد (الاهتمام العاطفي) في المرتبة الأولى وبمستوى متوسط وبمتوسط حسابي (3.44) وانحراف معياري (0.59)، بينما جاء بعد (الألم الشخصي) في المرتبة الأخيرة وبمستوى متوسط وبلغ متوسطه الحسابي (3.32) وانحرافه المعياري (0.65).

ويمكن عزو السبب في أن مستوى التمثل العاطفي لدى عينة من الطلبة اللاجئين السوريين في مدارس

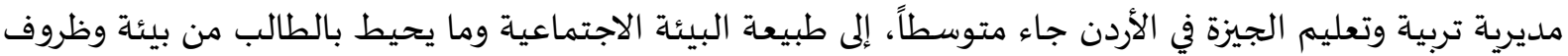
في بلد اللجوء، بالإضافة إلى نمط الثقافة السائد بحيث لا تتوفر للطالب الفرصة الكافية لتجربة مشاعر عدم الراحة والقلق الخاصة بالطرف الآخر الذي يشهد خبرة سلبية، علاوة عدم التركيز في توفير الفرص التدريبية لهذه الفئة من بن لهن

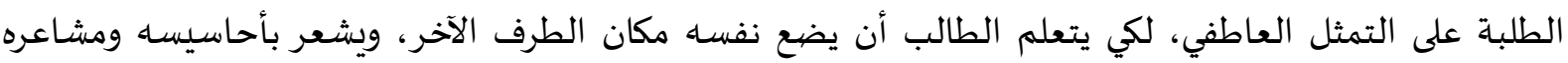
وانفعالاته.

وتتفق هذه النتيجة مع دراسة عبد الهادي والبسطامي (Abdel Hadi, 2017) والتي توصلت إلى وجود مستوى متوسط من التمثل العاطفي لدى الطلبة.

النتائج المتعلقة بالسؤال الثاني: ما مستوى الهناء الذاتي لدى طلبة المرحلة الأساسية العليا في مدارس مديرية التربية والتعليم بلواء الجيزة في الأردن؟ للإجابة على السؤال تم حساب المتوسطات الحسابية والانحرافات المعيارية، والجدول (10) يبين ذلك: 
جدول (10) المتوسطات الحسابية والانحرافات المعيارية لمستوى الهناء الذاتي لدى عينة من الطلبة اللاجئين السوريين في مدارس مديرية تربية وتعليم الجيزة في الأردن مرتبة تنازليا بحسب المتوسطات

\begin{tabular}{|c|c|c|c|c|c|}
\hline المستوى & الرتبة & الانحراف & المتوسط الحسابي & المجال & $\hat{\imath}$ \\
\hline متوسط & 1 & .60 & 3.34 & الدراسي & 2 \\
\hline متوسط & 2 & .57 & 3.33 & العلاقات الاجتماعية & 3 \\
\hline متوسط & 3 & .51 & 3.25 & الأسـري & 1 \\
\hline متوسط & 4 & .48 & 3.23 & الانفعالي & 4 \\
\hline متوسط & - & .46 & 3.28 & 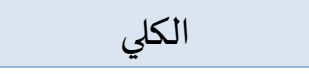 & \\
\hline
\end{tabular}

يلاحظ من خلال الجدول (10) أن مستوى الهناء الذاتي لدى عينة من الطلبة اللاجئين السوريين في مدارس ماس مديرية تربية وتعليم الجيزة في الأردن قد جاء متوسطاً إذ جاء متوسطه الحسابي (3.28) وانحرافه معياري (0.46)،

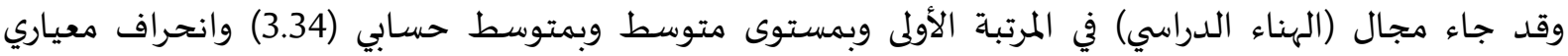

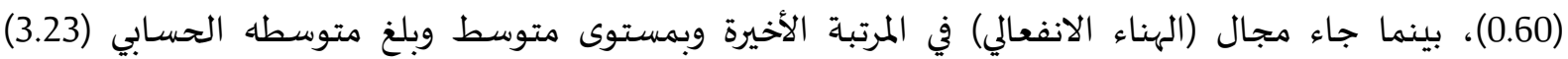
وانحرافه المعياري (0.48). ويمكن عزو السبب الى ما أشار إليه بوثا وبويسين (Botha \& Booysen, 2013) في هذه النتيجة إلى الدور

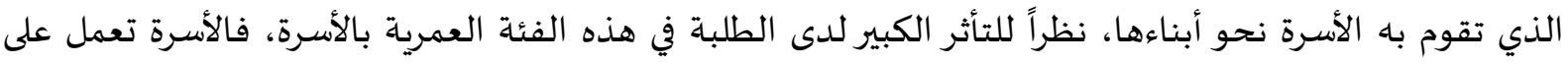

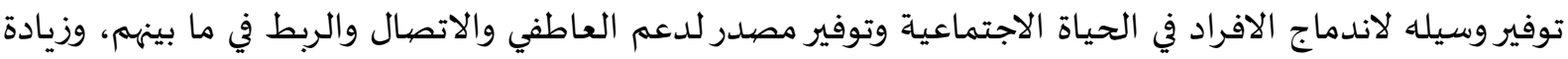
رضاهم عن الحياة والحفاظ على العلاقات، وبالتالي ورفع مستوى الهناء الذاتي لدى أبناءهاء الدها.

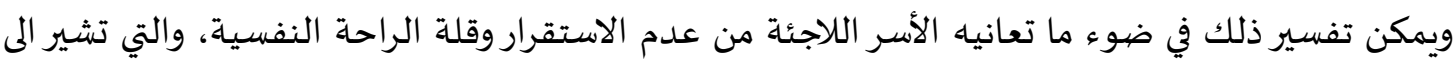
الصحة النفسية للفرد؛ وبالتالي تؤثر على عدم الاطمئنان والسكينة، الامر الذي يؤثر سلباً على مستوى الهناء الذاء الذاتي،

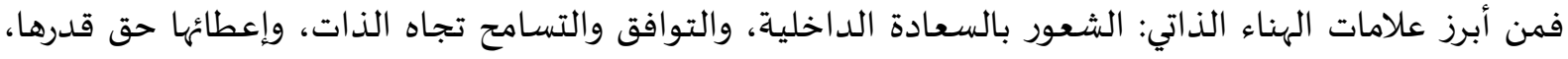
والقدرة على استغلال الخبرات الإيجابية اليومية بشكل فاعل؛ فالهناء هو الشعور بالسكينة الداخلية والطمأنينة.

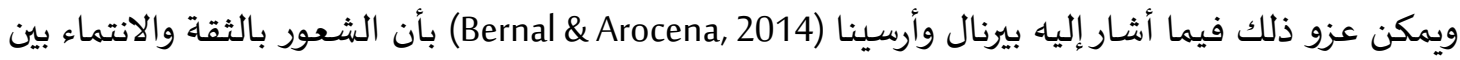
افراد الأسرة عاملان يرتبطان بشكل قوى بتماسك الاسرة والرضا الاسري والقدرة على الصمود وان الرفاه الاسري يتأثر بالتغيرات التي تصيب الاسر التي تتسم بالمرونة وتساعد على كيفية عملها فالطقوس الأسرية المتمثلة في التفاعل بين افرادها والحب والحفاظ على علاقات وثيقه وحل النزاعات و تعزيز التماسك لدى وتقديم الدعم الاجتماعي والعاطفي من المؤشرات الدالة على الهناء والرضا عن الحياه الأسرية. وتختلف هذه النتيجة مع دراسة (الخطيب والقرعان، 2020) والتي أشارت إلى أن مستوى الهناء الذاتي لدى الطلبة كان مرتفعاً. نتيجة السؤال الثالث: هل توجد علاقة ارتباطيه ذات دلالة إحصائية عند مستوى (م>0.05) بين التمثل

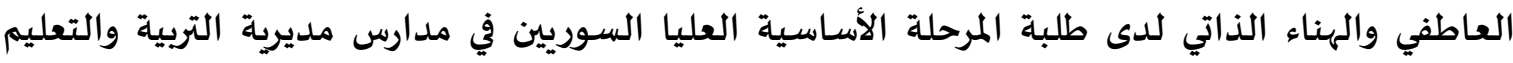
بلواء الجيزة؟ وللإجابة عن السؤال تم استخدام معامل ارتباط بيرسون لمعرفة العلاقة بين التمثل العاطفي والهناء الذاتي لدى عينة من الطلبة اللاجئين السوريين في مدارس مديرية تربية وتعليم الجيزة في الأردن كما في الجدول (11): 
جدول (11) معاملات ارتباط بيرسون بين التمثل العاطفي والهناء الذاتي لدى عينة من الطلبة اللاجئين السوريين في مدارس مديرية تربية وتعليم الجيزة في الأردن بئن

\begin{tabular}{|c|c|c|c|c|c|}
\hline 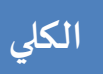 & الانفعالي & العلاقات الاجتماعية & الدراسي & الأسري & التمثل العاطفي الهناء الذاتي \\
\hline $.497^{* *}$ & $.451^{* *}$ & $.427^{* *}$ & $.391^{* *}$ & $.441^{* *}$ & الخيال \\
\hline $.491^{* *}$ & $.432^{* *}$ & $.433^{* *}$ & $.338^{* *}$ & $.504^{* *}$ & الاهتمام العاطفي \\
\hline $.470^{* *}$ & $.453^{* *}$ & $.352^{* *}$ & $.346^{* *}$ & $.473^{* *}$ & الأخذ بالاعتباروجهة نظر الآخر \\
\hline $.433^{* *}$ & $.415^{* *}$ & $.404^{* *}$ & $.278^{* *}$ & $.401^{* *}$ & الألم الشخصي \\
\hline $.587^{* *}$ & $.544^{* *}$ & $.502^{* *}$ & $.421^{* *}$ & $.562^{* *}$ & 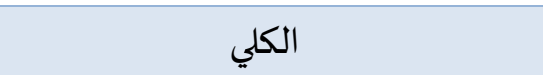 \\
\hline
\end{tabular}

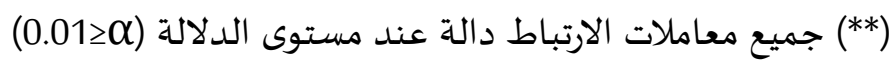

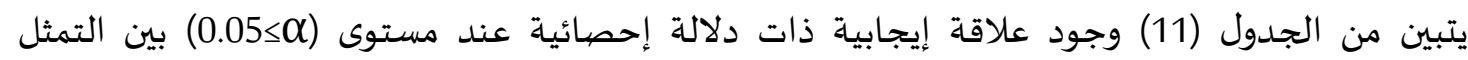

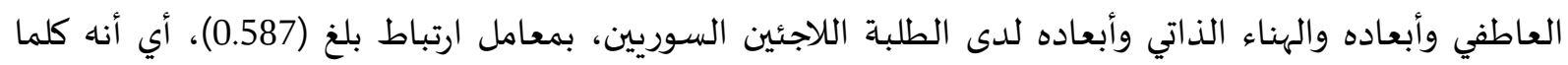

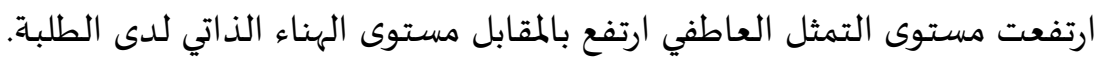

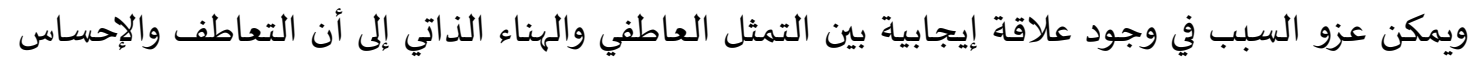

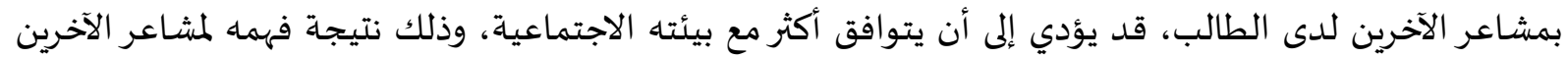

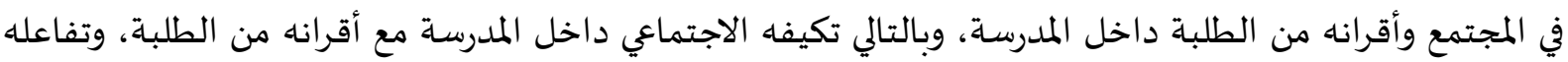

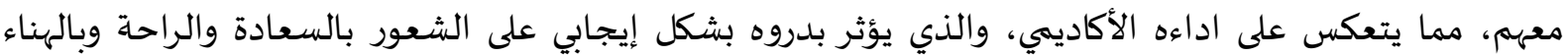
الذاتي لديه، وهذا ما أكدت عليه دراسة فاليكين وجابريلافيكيوت (Valickiene \& Gabrialaviciute, 2015).

نتيجة السؤال الرابع: ما القدرة التنبؤية لمجالات التمثل العاطفي في الهناء الذاتي لدى طلبة المرحلة

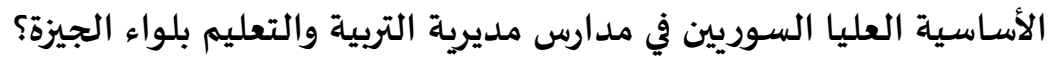
للإجابة عن السؤال تم استخراج رسم نتائج تحليل الانحدار الخطي بين التمثل العاطفي والهناء الذاتي كما

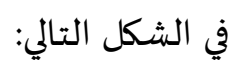

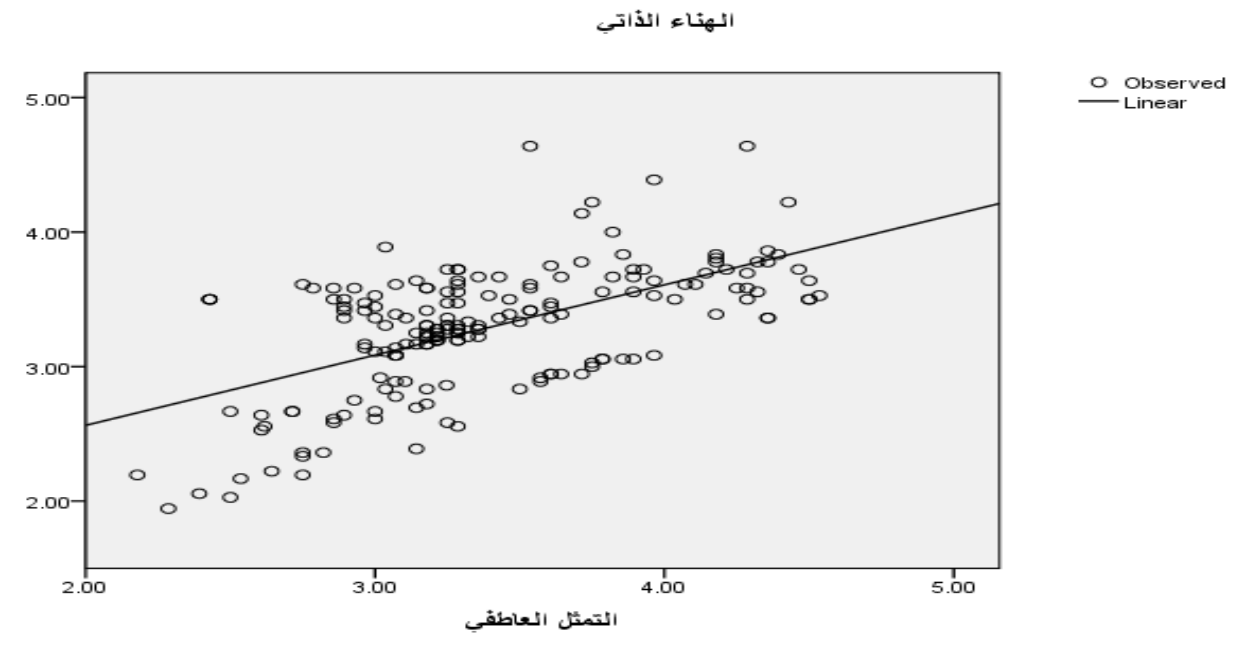


وفيما يلي تحليل التباين للانحدار الخاص بمريع معامل الارتباط الدال على العلاقة بين التمثل العاطفي

$$
\text { والهناء الذاتي والجدول (12) يبين ذلك: }
$$

جدول (12) تحليل التباين للانحدار الخاص بمربع معامل الارتباط الدال على العلاقة بين التمثل العاطفي

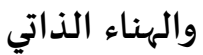

\begin{tabular}{|c|c|c|c|c|c|c|}
\hline التحدامل & الدلالة & ف & متوسط المربعات & درجات & مجموع المربعات & مصهدر \\
\hline \multirow{3}{*}{0.345} & .000 & 96.208 & 13.640 & 1 & 13.640 & الانحد ار \\
\hline & & & .142 & 183 & 25.946 & الخطأ \\
\hline & & & & 184 & 39.586 & الكلي \\
\hline
\end{tabular}

يلاحظ من الجدول (12) وجود أثر ذو دلالة احصائية لمتغير التمثل العاطفي في الهناء الذاتي، حيث كانت قيمة (ف)= (96.208)، حيث فسر متغير التمثل العاطفي بما نسبته (34.5\%) من التباين الكلي في الهناء الذاتي، مما

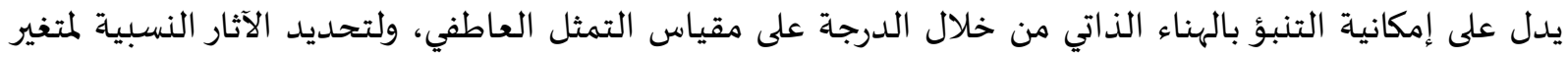

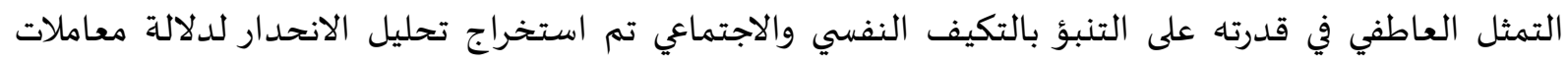

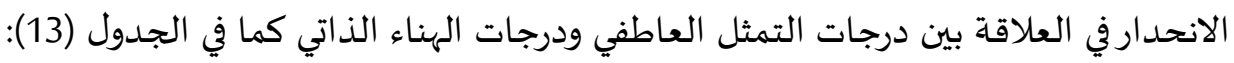

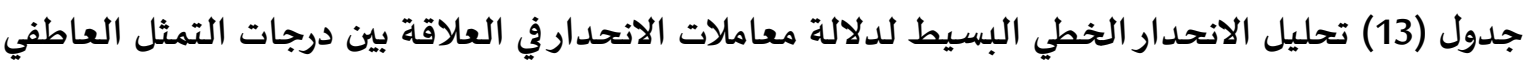
ودرجات الهناء الذاتي

\begin{tabular}{|c|c|c|c|c|c|}
\hline الدلالة & قيمة (ت) & 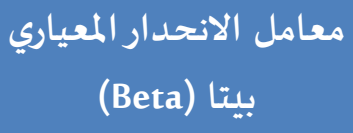 & الخطأ المعياري & $\begin{array}{l}\text { معامل الانحدار غير (b) (bارير } \\
\text { (b) }\end{array}$ & 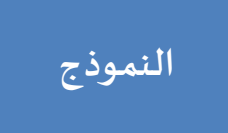 \\
\hline .000 & 8.345 & & .182 & 1.519 & ثابت الانحدار \\
\hline .000 & 9.809 & .587 & .053 & .522 & التمثل العاطفي \\
\hline
\end{tabular}

يلاحظ من الجدول (13) أن قيمة معامل الانحدار المعياري بيتا (Beta) بلغت (0.587) وهي ذات دلالة

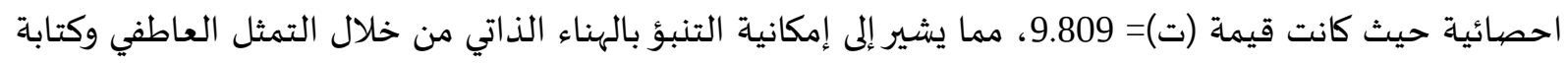
معادلة الانحدار كما يلي:

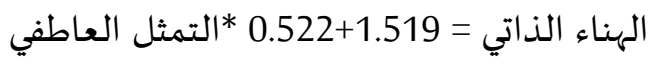

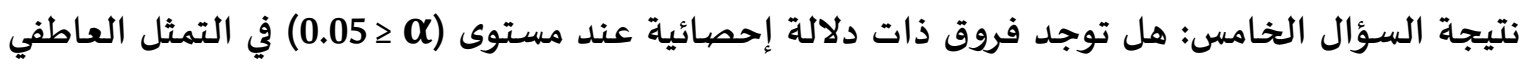

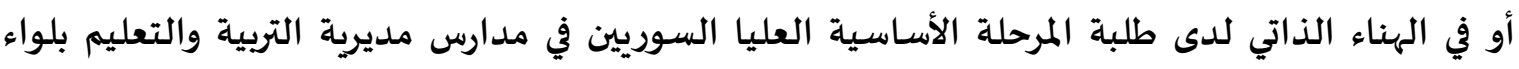

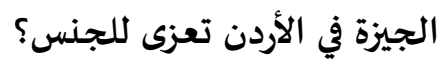

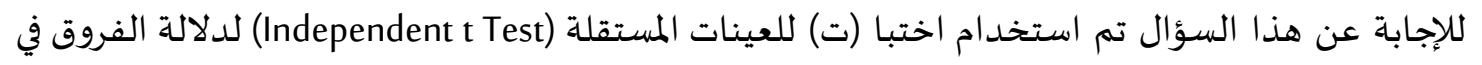

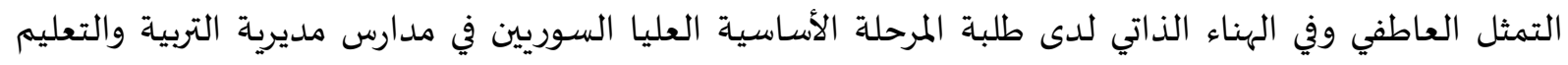
بلواء الجيزة في الأردن تبعا للجنس؛ وكانت النتائج كما يبينها الجدولان (14+15) وعل النحو الآتي: 


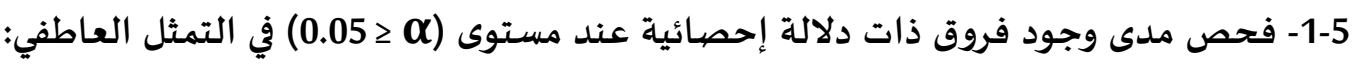

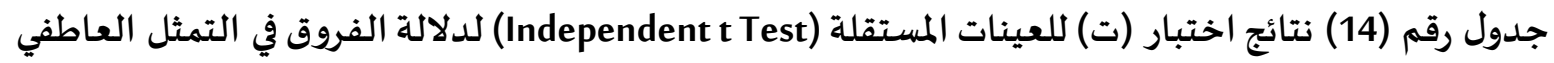
لدى طلبة المرحلة الأساسية العليا السوريين في مدارس مديرية التربية والتعليم بلواء الجيزة في الأردن تبعا لمتغير

\begin{tabular}{|c|c|c|c|c|c|c|c|}
\hline \multicolumn{8}{|c|}{ للجنس } \\
\hline الدلالة & قيمة (ت) & الحربة & الانحراف & المتوسط الحسابي & 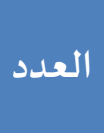 & الجنس & المجال \\
\hline \multirow{2}{*}{.011} & \multirow{2}{*}{-2.569} & \multirow{10}{*}{183} & .66 & 3.27 & 116 & ذكور & \multirow{2}{*}{ الخيال } \\
\hline & & & .78 & 3.55 & 69 & إناث & \\
\hline \multirow{2}{*}{.010} & \multirow{2}{*}{-2.619} & & .52 & 3.35 & 116 & ذكور & \multirow{2}{*}{ الاهتمام العاطفي } \\
\hline & & & .67 & 3.58 & 69 & إناث & \\
\hline \multirow{2}{*}{.037} & \multirow{2}{*}{-2.106} & & .57 & 3.32 & 116 & 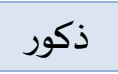 & الأخذ بالاعتباروجهة \\
\hline & & & .69 & 3.52 & 69 & إناث & نظر الطرف الأخر \\
\hline \multirow{2}{*}{.080} & \multirow{2}{*}{-1.762} & & .59 & 3.25 & 116 & ذكور & \multirow{2}{*}{ الألم الشخصي } \\
\hline & & & .72 & 3.42 & 69 & إناث & \\
\hline \multirow{2}{*}{.005} & \multirow{2}{*}{-2.830} & & .45 & 3.30 & 116 & ذكور & \multirow{2}{*}{ التمثل العاطفي الكلي } \\
\hline & & & .60 & 3.52 & 69 & إناث & \\
\hline
\end{tabular}

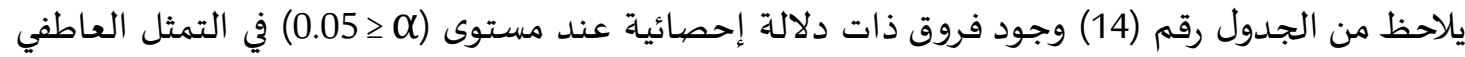
لدى طلبة المرحلة الأساسية العليا السوريين في مدارس مديرية التربية والتعليم بلواء الجيزة في الأردن تبعا للجنس تعزى للجنس، حيث بلغت قيمة (ت) المحسوبة للكلي= (- 2.830)، ووجود فروق في الأبعاد الثلاثة (الخيال، الاهتمام العاطفي، الأخذ بالاعتبار وجهاة نظر الطرف الأخر) حيث بلغت قيم (ت) = (- 2.569، - 2.919، - 2.106،

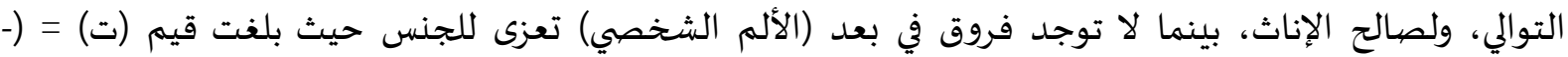

ويمكن تفسير السبب في وجود فروق في التمثل العاطفي لدى طلبة المرحلة الأساسية العليا السوريين بين

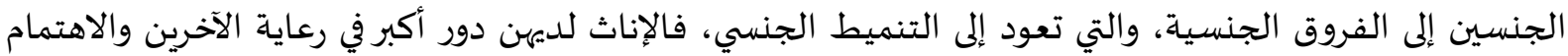

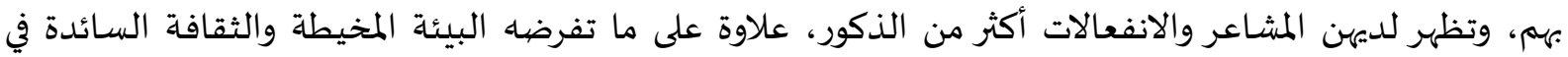

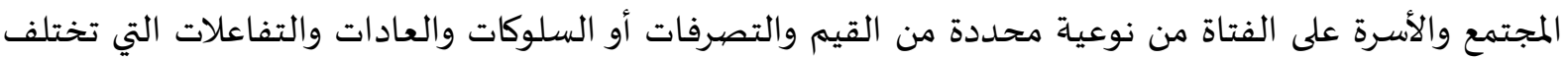

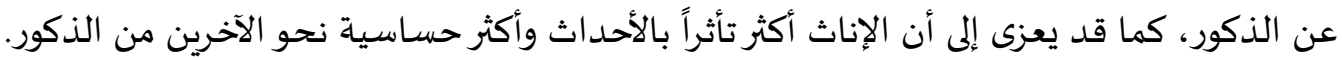

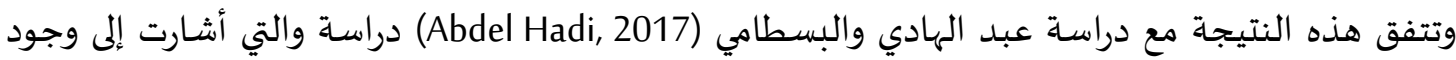
فروق في التمثل العاطفي ولصالح الإناث. 2-5- فحص مدى وجود فروق ذات دلالة إحصائية عند مستوى (X) 20.05$)$ في الهناء الذاتي: 
جدول (15) نتائج اختبار (ت) للعينات المستقلة (Independent t Test) لدلالة الفروق في الهناء الذاتي لدى عينة

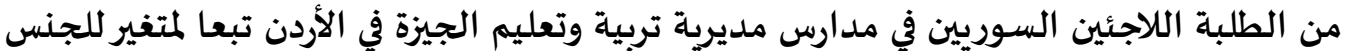

\begin{tabular}{|c|c|c|c|c|c|c|c|}
\hline الدلالة & قيمة (ت) & الحربة دربة & الالمعياري & الحستوسط & العدد & الجنس & المجال \\
\hline \multirow{2}{*}{.849} & \multirow{2}{*}{-.191} & \multirow{10}{*}{183} & .45 & 3.25 & 116 & ذكور & \multirow{2}{*}{ الأسري } \\
\hline & & & .60 & 3.26 & 69 & 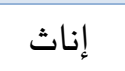 & \\
\hline \multirow{2}{*}{.895} & \multirow{2}{*}{.132} & & .51 & 3.34 & 116 & ذ كور & \multirow{2}{*}{ الدراسي } \\
\hline & & & .73 & 3.33 & 69 & إناث & \\
\hline \multirow{2}{*}{.854} & \multirow{2}{*}{-.184} & & .52 & 3.32 & 116 & 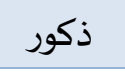 & \multirow{2}{*}{ العلاقات } \\
\hline & & & .66 & 3.33 & 69 & إناث & \\
\hline \multirow{2}{*}{.957} & \multirow{2}{*}{.055} & & .43 & 3.23 & 116 & ذكور & \multirow{2}{*}{ الانفعالي } \\
\hline & & & .56 & 3.23 & 69 & 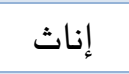 & \\
\hline \multirow{2}{*}{.970} & \multirow{2}{*}{-.037} & & .40 & 3.28 & 116 & 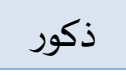 & \multirow{2}{*}{ الهناء الذاتي الكلي } \\
\hline & & & .56 & 3.28 & 69 & 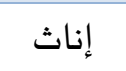 & \\
\hline
\end{tabular}

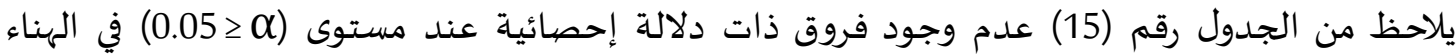
الذاتي لدى عينة من الطلبة اللاجئين السوريين في مدارس مديرية تربية وتعليم الجيزة في الأردن تعزى للجنس، حيث

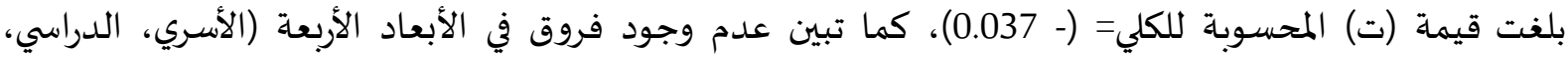

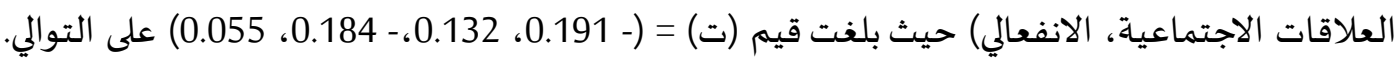
وقد تعزى هذه النتيجة إلى تقارب الظروف الأسرية والظروف الدراسية والاجتماعية بين الطلاب والطالبات،

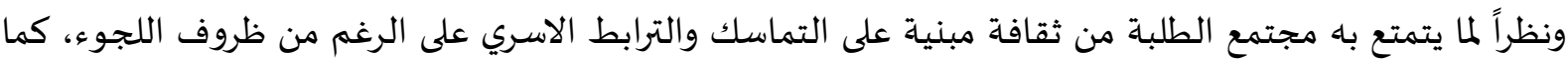

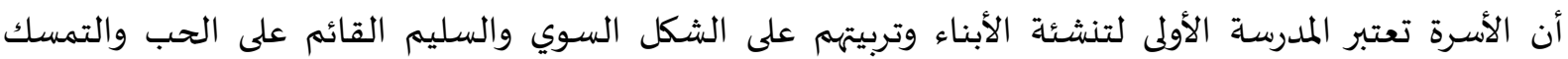
بالآداب والاخلاق الاسلامية. كما قد يرجع السبب الى ان كلا الجنسين يعيشان في بيئة ثقافية واجتماعية متشابهة.

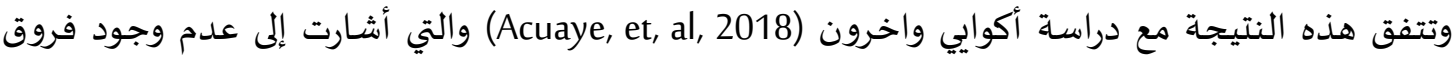

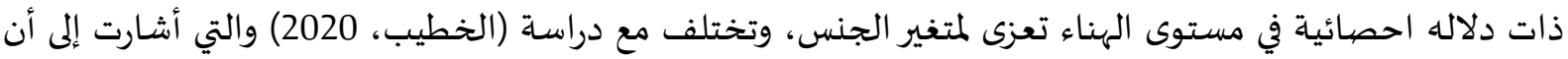
الفروق في مستوى الهناء الذاتي تعزى للذكور.

\section{التوصيات والمقترحات.}

$$
\text { بناء على النتائج يوصي الباحث ويقترح الآتي: }
$$

1- - ضرورة أن تقوم المدارس ومن خلال المرشدين التربويين ببرامج ارشادية لتحسين مستوى التمثل العاطفي لدى الطلبة وخاصة من اللاجئين السوريين وتدريههم عليه، وخاصية الطلبة الذكور. 2- توسيع دور المرشد الطلابي في المدارس السورية أو التي يوجد بها طلبة سوريين لعمل برامج إرشادية وقائية نمائية علاجية تنمي وتعالج حالات عدم الهناء الذاتي لدى أبناء هذه الأسر. 3- ضرورة التركيزوالاهتمام بقضايا اللاجئين الاقتصادية والاجتماعية وتناولها من خلال الاعلام. 4- إجراء المزيد من الدراسات في المستقبل على عينات أخرى ومتغيرات جديدة على الطلبة السوريين اللاجئين. 
5- إجراء دراسـات تجريبية لفحص فاعلية البرامج المستندة إلى تنمية التمثل العاطفي لدى الطلبة السوريين اللاجئين في مستوى الهناء الذاتي لديهم .

\section{قائمة المراجع}

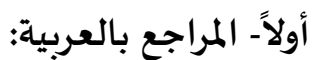

- ميدة، محمد (2013). الهناء الذاتي وعلاقته ببعض متغيرات الشخصية لدي طلاب الجامعة. المجلة المصرية

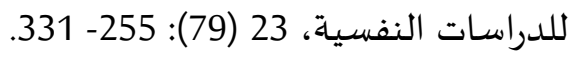
حميدة، محمد (2019). فعالية برنامج قائم على اليقظة الذهنية في تنمية التدفق النفسي وأثره على السعادة

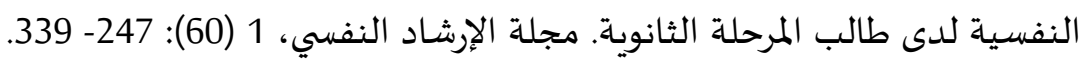
الخطيب، لبنى؛ والقرعان، جهاد (2020). مستوى الهناء الذاتي وعلاقته بالطموح والايثار لدى عينة من طلبة البهادية جامعة مؤتة، المجلة الدولية التربوية المتخصصية، ولفرعان، 9 (1): 200- 234.

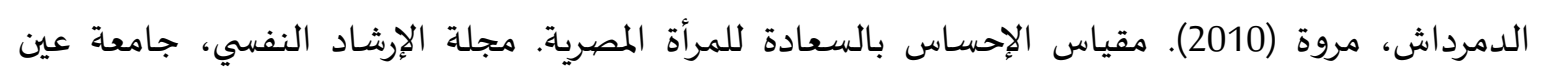
شمس، 27. سلامي، دلال (2016). الذكاء العاطفي: مدخل نظري. مجلة الدراسات والبحوث الاجتماعية، جامعة الشهيد

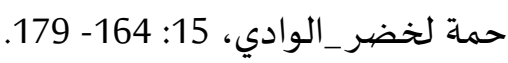

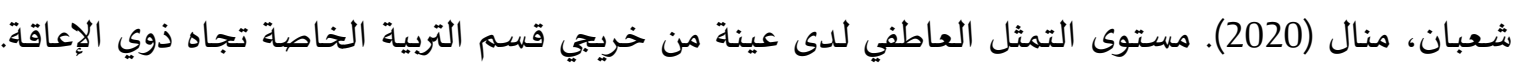

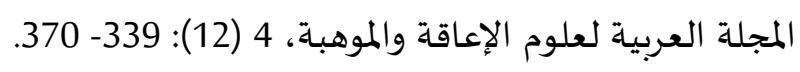

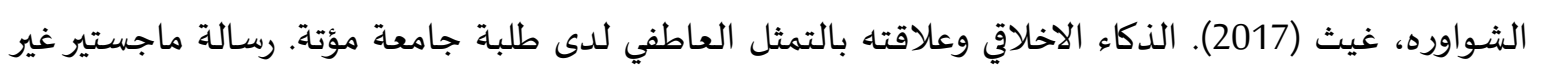
منشورة: جامعة مؤتة.

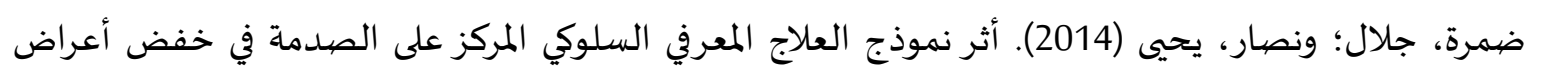

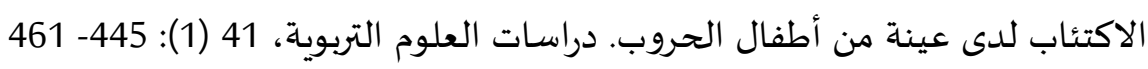
- الطيب، محمد؛ والهباص، سيد (2009). الصحة النفسية وعلم النفس الإيجابي، مصرئ مكتبة النهضية المصرية.

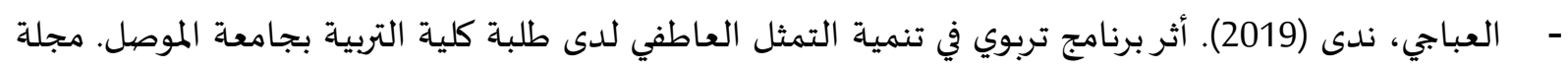
أبحاث كلية التربية الأساسية بجامعة الموصل، أنرئ، 16 (1): 195- 210.

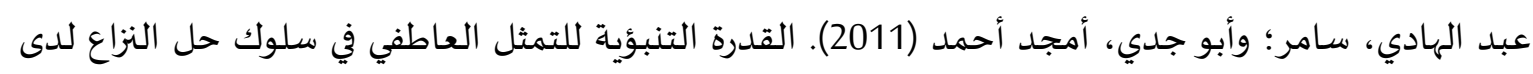

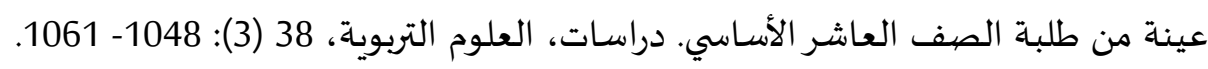

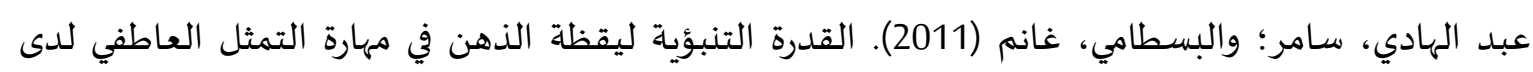

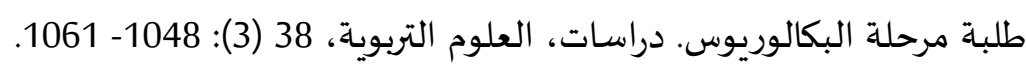
عثمان، حباب عبد الحي (2009). الذكاء الوجداني العاطفي- الانفعالي- الفعال مفاهيم وتطبيقات. الأردن: دار الئورات

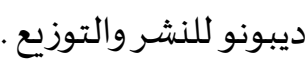
عكاشة، أحمد (2008). الطب النفسي المعاصر. ط4، مصرو: مكتبة الأنجلو المبلو المصرية.

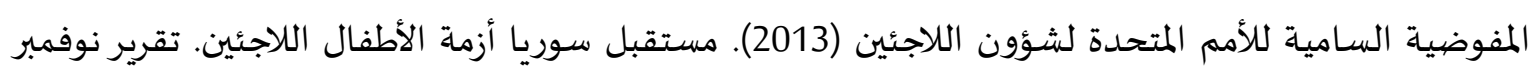
.2013 يوسف، جمعة (2007). إدارة الضغوط. ط1، مصر: مركز تطوير الدراسات للنشر. 


\section{ثانياً - المراجع بالإنجليزية:}

- Abdel Hadi, Samer Adnan (2017). Predicting Ability for Mindfulness in Empathy Skill: A Study of Undergraduate Students of Abu Dhabi University. International Journal for Research in Education: Vol. 41: Iss. 4, Article 5.

- Acuaye, H. E, Mitchell, M. D., Saliba. Y., Oh, S. \& Heard, N. (2018). Optimism in trauma and growth: A path analysis of former was- related displaced persons. Journal of Pedagogical Research, 2 (1):16- 29.

- Bernal, A. \& Arocena, F. (2014). Established satisfaction with family life scale factor in middle school and high school adolescents. Psicogente, 17 (31), 226- 240

- Botha, F. \& Booysen, F. (2013). Family functioning and life satisfaction and happiness in South African households. Social Indicators Research, 119 (1), 163- 18

- Diener, E. (2000). Subjective well- being: The science of happiness and a proposal for a national index. American Psychologist.

- Diener, E., \& Chan, M., Y. (2011). Happy People live longer subjective well- being contributes to health and longevity. Applied psychology: Health and Weel -Being. 3 (1): 1- 43.

- Jolliffe, D. \& Farrington, D. (2009). Examining the Relationship between Empathy and Self- Reported Offending. Legal and Criminological Psychology, 12 (1): 265- 286.

- Malavia, R. \& Punia, N. (2015). psychological well- being of year college students. Indian Journal of Educational studies, 1 (2): 60- 68.

- UNHCR, United Nations High Commissioner for Refugees - (2015). Syria Regional Refugees in Jordan. Retrieved on 1/9/2021 from: https://www. UNHCR. com/html.

- Valickiene, R. \& Gabrialaviciute, I. (2015). The Role of School Context On Subjective Well- Being and Social Well- Being in Adolescence. Procedia- Social and Behavioral Sciences, 191: 2988- 2992.

- Wied, M. Branje, S. and Meeus, W. (2006). Empathy and Conflict Resolution in Friendship Relations among Adolescents. Aggressive Behavior, 33 (1): 48- 55. 